\title{
A Winkler model for suction caisson foundations in homogeneous and non-homogeneous linear elastic soil
}

\author{
Stephen K. Suryasentana ${ }^{1}$ \\ Harvey J. Burd² \\ Byron W. Byrne ${ }^{3}$ \\ Avi Shonberg 4
}

\section{Affiliations}

${ }^{1}$ Department of Civil and Environmental Engineering, University of Strathclyde, Glasgow, UK; formerly Department of Engineering Science, University of Oxford, Oxford, UK

(Orcid: 0000-0001-5460-5089)

2 Department of Engineering Science, University of Oxford, Oxford, UK (Orcid: 0000-0002-8328-0786)

${ }^{3}$ Department of Engineering Science, University of Oxford, Oxford, UK (Orcid: 0000-0002-9704-0767)

${ }^{4}$ Ørsted Wind Power, London, UK

\section{Corresponding author information}

Stephen Suryasentana

stephen.suryasentana@strath.ac.uk 


\section{Abstract}

Suction caisson foundations provide options for new foundation systems for offshore structures, particularly for wind turbine applications. During the foundation design process, it is necessary to make reliable predictions of the stiffness of the foundation, since this has an important influence on the dynamic performance of the overall support structure. The dynamic characteristics of the structure, in turn, influence its fatigue life. This paper describes a thermodynamically-consistent Winkler model, called OxCaisson, that delivers computationally efficient estimates of foundation stiffness for caissons installed in homogeneous and nonhomogeneous linear elastic soil, for general six degrees-of-freedom loading. OxCaisson is capable of delivering stiffness predictions that are comparable to those computed with threedimensional finite element analysis, but at a much lower computational cost. Therefore, the proposed model is suited to design applications where both speed and accuracy are essential, such as large-scale fatigue assessments of offshore wind farm structures. The paper demonstrates that the OxCaisson model can also be applied to short rigid monopile foundations.

\section{KEYWORDS}

Suction caisson foundations, soil-structure interaction, offshore engineering, Winkler model 


\section{INTRODUCTION}

There is increasing interest in employing suction caisson foundations (also referred to as suction bucket foundations, see Fig. 1a) for offshore wind turbine support structure applications, because of potential advantages such as quiet installation (important for projects with noise restrictions), faster installation and simpler decommissioning (Byrne \& Houlsby, 2003) compared with other foundation options. The design of suction caissons in this application relies on the availability of efficient procedures to predict foundation stiffness (relevant to dynamic analyses of the overall structure) and strength (to facilitate the analysis of storm loading events). However, the range of available design procedures for suction caissons in this application is rather more limited than is the case for monopile foundations, which are currently the dominant foundation system for offshore wind turbines in shallow waters.

This paper describes a new design model - 'OxCaisson' - to predict the stiffness of suction caisson foundations, especially for wind turbine support structure applications. The design model is developed for full six degrees-of-freedom loading and is calibrated for homogeneous and non-homogeneous elastic soils for which the stiffness varies with depth. OxCaisson is fast to compute; it is therefore well-suited to the design of offshore wind farms, which typically require a large number of computations to assess different foundation geometries and wind farm layouts to determine optimal configurations.

The OxCaisson model is based on an underlying concept, known as the Winkler assumption (Winkler 1867), in which the soil reactions acting on the foundation are considered to be functions of the local caisson displacement and rotation only. The spatial coupling that occurs within the soil is therefore excluded from the model. This approach has the advantage of simplicity, although the shortcomings of the Winkler assumption has certain consequences for the calibration of the model. The Winkler approach also means that the design model is only reliable for the particular parameter space that was employed to calibrate it.

The Winkler modelling concept forms the basis of the ' $p$-y method' (e.g. API 2010, DNV 2016) that is widely used for the design of piles (including monopiles for offshore wind applications) that are subjected to lateral loading. Standard forms of the $p-y$ method employ a single soil reaction component, namely a lateral distributed load, that is related to the local lateral pile displacement by a nonlinear function ( $p-y$ curve) that is calibrated to the local soil conditions. Although the accuracy of current forms of the $p-y$ method has been questioned (e.g. Doherty \& Gavin 2011), its widespread use is indicative of the usefulness of the Winkler concept as the basis for simplified design models. Piles subjected to axial loading are routinely designed using another Winkler-type modelling approach known as the ' $t-z$ method' (API 2010, DNV 2016). The established nature of the $p-y$ and $t-z$ methods supports the use of the Winkler approach in the current work. 


\section{Existing Winkler models}

Extended forms of the Winkler model have been previously developed for solid caisson foundations embedded in linear elastic soil (Gerolymos \& Gazetas 2006a, Tsigginos et al. 2008 and Varun et al. 2009) in which four separate soil reactions (distributed lateral load and moment reactions on the caisson shaft and horizontal force and moment reactions at the base) are employed. These models are calibrated by inferring the local soil reaction components based on the overall stiffness of the foundation computed at a convenient reference point (e.g. at ground level); this general calibration approach is referred to in the current paper as 'inferred Winkler model'. Suction caisson foundations (the focus of the current paper) comprise a steel lid and skirt structure that is embedded in the ground by suction; the performance of the caisson is governed by interactions between the base of the soil plug and the surrounding ground, as well as interactions between the exterior surface of the skirt and the surrounding ground.

Conversely, solid caissons consist of a homogeneous mass of embedded material, typically concrete. Solid and suction caissons with the same diameter and embedded length are likely to exhibit certain differences in behaviour (with solid caissons likely to be stiffer). Nevertheless, modelling procedures developed for solid caissons are considered likely to be broadly applicable to the suction caisson configuration considered in the current paper.

An enhanced form of the $p-y$ method-known as the 'PISA design model' (Byrne et al, 2019) has recently been developed for the design of monopiles with embedment ratios, $L / D$, in the range $2 \leq L / D \leq 6$ (where $L$ is embedded length and $D$ is foundation diameter). Consistent with the Gerolymos \& Gazetas (2006a,b), Tsigginos et al. (2008) and Varun et al. (2009) models, the PISA design model employs four separate soil reaction components, although the model is further enhanced to incorporate nonlinear soil behaviour. The PISA design model employs 3D finite element analyses to develop site-specific calibrations of the local soil reaction models. Importantly, the functions employed to represent the soil reactions in the PISA model are calibrated at a local level, using soil-pile tractions computed in the calibration analyses.

Modelling approaches such as this, that calibrate the model at a local level, are referred to here as 'calibrated Winkler models'.

Inferred Winkler models are calibrated to ensure that the performance of the model in predicting the overall stiffness of the foundation is satisfactory. There is no guarantee or expectation, however, that the model provides a realistic representation of the soil-foundation interaction behaviour that actually occurs at a local level. Conversely, calibrated Winkler models consider the actual local behaviour at the soil-foundation interface, as computed using the calibration analyses. Provided that a suitable local model can be formulated and calibrated, it is expected that the overall performance of the foundation will be predicted to a reasonable level of accuracy by the model. Although Winkler approaches can only provide an imperfect representation of the physics of the soil-foundation interaction, calibrated models seem likely to provide a closer representation of reality than inferred models. 
OxCaisson is a linear Winkler model for the analysis of suction caisson foundations embedded in homogeneous and non-homogeneous elastic ground. Local soil stiffness coefficients are calibrated using data from 3D finite element calibration analyses. Data interpreted from the 3D analyses demonstrate that the lateral and rotational response of the soil is coupled at a local level. As it is desirable for OxCaisson to provide a realistic representation of the caisson behaviour at the soil-foundation interface, this local coupling is included in the OxCaisson model. This local coupling means that the stiffness coefficients employed in the current model cannot be compared directly with previous models (e.g. Gerolymos \& Gazetas 2006a; Tsigginos et al. 2008; Varun et al. 2009) in which this local coupling is absent. OxCaisson also incorporates the influence of soil Poisson's ratio $v$ on the value of the local stiffness coefficients, which is important as some of the local stiffness coefficients (e.g. vertical stiffness) may vary as much as $40 \%$ for $0 \leq v \leq 0.49$. This is an improvement over previous Winkler caisson models (e.g. Varun et al. 2009) in which the influence of soil Poisson's ratio is not considered.

Several Winkler models for solid caisson foundations embedded in elastic soils have been previously proposed in which the 'inferred' Winkler modelling approach is employed. Although models of this form can be made to approximate the overall foundation stiffness obtained from 3D finite element analysis, they do not consider the local soil-foundation interactions.

Consequently, they do not provide insights into the local physics of the soil response. The OxCaisson model adopts the alternative 'calibrated' approach in which closed-form formulations are derived for the Winkler soil reactions (for the full six degrees-of-freedom load space) that closely approximate the local physics of the soil-foundation interaction as determined from 3D calibration analyses. It is considered that this procedure provides a more fundamental basis for the development of more complex design models (e.g. for non-linear dynamics analyses, elastoplastic soil behaviour or multi-directional cyclic loading design models) than the inferred modelling approach. Moreover, the calibrated approach results in more generalised soil reactions that are not tightly coupled with the structural properties of the foundation used for calibration.

Alternative non-local Winkler models have been previously developed for pile foundations (e.g. Versteijlen et al. 2018). These models have certain advantages for elastic analysis, but they cannot readily be developed for non-linear soil behaviour. Non-local models are therefore not further considered in the current work.

\section{Existing macro-element models}

A macro-element model to estimate the global stiffness coefficients for suction caissons embedded in homogeneous and non-homogeneous elastic soil have previously been proposed by Doherty et al. (2005) using the scaled boundary finite-element method. The results presented in Doherty et al. (2005) relate to caissons with uniform skirt thickness. The Winkler approach developed in the current paper offers certain advantages over this approach, such as enabling 
caisson design optimisation by varying the wall thickness along the caisson skirt length; foundation optimisation of this sort has been previously described for monopile design by Kallehave et al. (2015).

The current paper describes an OxCaisson calibration for soils with uniform values of Poisson's ratio in the range $0 \leq v \leq 0.49$ and for caissons with embedment ratios $0 \leq L / D \leq 2$. This embedment ratio range is considered to be representative of caissons for offshore wind applications. The calibration presented in the current paper is restricted to soils with a shear modulus $G$ that varies with depth according to,

$$
G=G_{\mathrm{R}}\left(\frac{2 z}{D}\right)^{\alpha}
$$

where $G_{\mathrm{R}}$ is a reference stiffness, $\alpha$ is a parameter $(0 \leq \alpha \leq 1), z$ is distance below the ground surface and $D$ is the caisson diameter (see Fig. 1). The OxCaisson model considers the complete set of six degrees-of-freedom of loading applied to the foundation at the reference point (RP) via the superstructure. It is initially calibrated for rigid caissons foundations, but the application of the model to flexible caissons (i.e. incorporating skirt flexibility) is also demonstrated.

\section{Applications of OxCaisson}

Although the current paper is concerned principally with caissons, it is of interest to consider whether the modelling framework is also applicable to monopiles. (In the context of simplified models, a monopile is considered to be equivalent to a caisson foundation in which the lid is absent.) Exploratory, 3D finite element calculations provide a means of identifying the foundation and soil configurations for which the rigid lid has a relatively small effect on the overall stiffness; in these cases, the design model developed in the current paper (for caissons) is considered also to be applicable to monopiles. This aspect of the paper draws on previous work by Efthymiou \& Gazetas (2018) that indicates, on the basis of 3D finite element studies, that the influence of the lid on the overall stiffness of a caisson foundation becomes increasingly less significant as the embedment ratio is increased.

A key application of OxCaisson is the formulation of foundation models to incorporate within an overall dynamic analysis of a wind turbine support structure for the purpose of estimating its fundamental natural frequency. Wind turbine structures during their lifetime are subjected to large numbers of relatively small amplitude cyclic loads, e.g. due to ambient wind and wave conditions. These loading cycles have the potential to cause high-cycle fatigue failures in the support structure. To minimise the risk of fatigue, it is important to ensure that the fundamental natural frequency of the system, for small amplitude loading, avoids the principal loading frequencies (to minimise dynamic amplification effects). Two key frequencies to avoid are the 
rotor frequency (1P) and the blade passing frequency (3P). A commonly employed design philosophy (e.g. Bhattacharya 2019), known as 'soft-stiff' design, is to ensure that the fundamental natural frequency of the support structure falls between the frequency ranges implied by the $1 \mathrm{P}$ and $3 \mathrm{P}$ loading. For current offshore systems, this typically implies a target natural frequency in the range $0.25-0.3 \mathrm{~Hz}$ (Bhattacharya 2019). Since, for this high-cycle fatigue design condition, the amplitude of the loading is relatively small low, linear elastic soil models are regarded as appropriate for design purposes (e.g. Arany et al. 2016, Jalbi et al. 2018). Additionally, since the frequencies of the applied loads are also relatively low, dynamic soil stiffness effects associated with radiation damping, as routinely incorporated in models intended for seismic analysis (e.g. Tsigginos et al. 2008) are typically considered negligible (e.g. Arany et al. 2016).

Consistent with the considerations outlined above, the current model employs linear frequencyindependent elasticity to represent the soil. It is acknowledged that the foundation may contribute a certain amount of damping to the overall support structure due to soil hysteresis (not included in the current model). In practical cases, however, the damping ratio contributed by the soil is small (typically less than 1\%, Arany et al. 2016); damping at this level has a minimal influence on the structural natural frequency.

Consistent with much previous work in this area, the coupling between the soil and foundation is represented in this study with tie constraints. The possibility of gapping and sliding is not incorporated in the model on the basis that these aspects are not considered to be significant for the low levels of loading that occur under ambient conditions.

\section{FORMULATION OF OXCAISSON}

\section{Problem definition}

The OxCaisson model considers a suction caisson, circular in plan, with skirt length $L$ and diameter $D$, embedded in an isotropic non-homogeneous elastic soil as shown in Fig. 1a. In developing the model, the foundation is constrained to deform as a rigid body, although the model is also applicable to cases when skirt flexibility is incorporated.

External loads $\mathbf{P}=\left[\begin{array}{lllllll}H_{x} & H_{y} & V & M_{x} & M_{y} & Q\end{array}\right]^{\mathrm{T}}$ are applied to the caisson at the reference point (RP), Fig. 1c. The corresponding energetically-conjugate global displacements at the RP are $\mathbf{U}=\left[\begin{array}{llllll}U_{x} & U_{y} & U_{z} & \Theta_{x} & \Theta_{y} & \Theta_{z}\end{array}\right]^{\mathrm{T}}$, Fig 1b. The purpose of the OxCaisson model is to estimate the global stiffness matrix, $\mathbf{K}$, where $\mathbf{P}=\mathbf{K U}$, for practical design applications. 
For a linear elastic system (such as the one considered here) $\mathbf{K}$ is guaranteed to be symmetric. It is also positive definite (for positive values of soil shear and bulk modulus). Moreover, geometric symmetry of the problem implies that the global stiffness matrix has the general form,

$$
\mathbf{K}=\left[\begin{array}{cccccc}
K_{H} & 0 & 0 & 0 & -K_{C} & 0 \\
0 & K_{H} & 0 & K_{C} & 0 & 0 \\
0 & 0 & K_{V} & 0 & 0 & 0 \\
0 & K_{C} & 0 & K_{M} & 0 & 0 \\
-K_{C} & 0 & 0 & 0 & K_{M} & 0 \\
0 & 0 & 0 & 0 & 0 & K_{Q}
\end{array}\right]
$$

where $K_{H}, K_{V}, K_{M}, K_{Q}$ and $K_{C}$ are independent stiffness coefficients that depend on the stiffness characteristics of the soil, the dimensions of the foundation and (for flexible caissons) the stiffness characteristics of the caisson structure.

\section{Cross sections}

The model is based on the kinematics of horizontal planes, known as 'cross sections'. Two types of cross sections are considered; 'skirt cross section' and 'base cross section'. Skirt cross sections are horizontal sections through the caisson skirt for $0<z<L$; the base cross section is the horizontal cross section at the base of the caisson (including the soil plug) at $z=L$ (Fig. 1a). Each cross section has associated with it a set of local cross section displacements (Fig 2a),

$$
\mathbf{u}=\left[\begin{array}{llllll}
u_{x} & u_{y} & u_{z} & \theta_{x} & \theta_{y} & \theta_{z}
\end{array}\right]^{\mathrm{T}}
$$

The corresponding local cross section load and moment soil reactions are (Fig 2b),

$$
\mathbf{p}=\left[\begin{array}{llllll}
h_{x} & h_{y} & v & m_{x} & m_{y} & q
\end{array}\right]^{\mathrm{T}}
$$

These local cross section displacements and soil reactions are defined with respect to a reference point $(\mathrm{RC})$ at the centre of each cross section. The local soil model employed in OxCaisson is specified by $\mathbf{p}=\mathbf{k} \mathbf{u}$ where $\mathbf{k}$ is the local stiffness matrix.

For a rigid caisson, the local skirt cross section displacements, $\mathbf{u}$, are related to the global caisson displacements, $\mathbf{U}$, by,

$$
\mathbf{u}=\mathbf{J}(z) \mathbf{U}
$$

where, 


$$
\mathbf{J}(z)=\left[\begin{array}{cccccc}
1 & 0 & 0 & 0 & z & 0 \\
0 & 1 & 0 & -z & 0 & 0 \\
0 & 0 & 1 & 0 & 0 & 0 \\
0 & 0 & 0 & 1 & 0 & 0 \\
0 & 0 & 0 & 0 & 1 & 0 \\
0 & 0 & 0 & 0 & 0 & 1
\end{array}\right]
$$

The cross section displacements at the base of the caisson are related to the global displacements by,

$$
\mathbf{u}=\mathbf{J}(L) \mathbf{U}
$$

This rigid caisson form of the model is employed to develop and calibrate the local stiffness coefficients (i.e. the coefficients in the local stiffness matrix, $\mathbf{k}$ ).

\section{Soil reactions}

Displacements of the caisson (due to external loads) will lead to the development of soil reactions at the soil-foundation interface. To calibrate the local stiffness model, $\mathbf{p}=\mathbf{k u}$, the cross section soil reactions $\mathbf{p}$ are determined directly from the local tractions $\mathbf{t}=\left[\begin{array}{lll}t_{x} & t_{y} & t_{z}\end{array}\right]^{\mathrm{T}}$ acting at the soil foundation interface, as determined from the 3D calibration analyses.

The soil reactions acting on the skirt, termed 'skirt soil reactions', are,

$$
\mathbf{p}^{\text {skirt }}=\left[\begin{array}{llllll}
h_{x}^{\text {skirt }} & h_{y}^{\text {skirt }} & v^{\text {skirt }} & m_{x}^{\text {skirt }} & m_{y}^{\text {skirt }} & q^{\text {skirt }}
\end{array}\right]^{\mathrm{T}}
$$

The first three terms in $\mathbf{p}^{\text {skirt }}$ relate to distributed loads in the $x, y$ and $z$ directions respectively. The $m_{x}^{\text {skirt }}$ and $m_{y}^{\text {skirt }}$ terms represent distributed moments and $q^{\text {skirt }}$ is distributed torque.

The skirt soil reaction vector is computed at specific depths from the local tractions, $\boldsymbol{t}$, determined from the 3D calibration analyses by,

$$
\mathbf{p}^{\text {skirt }}=\frac{D}{2} \int_{0}^{2 \pi}\left[\begin{array}{lllllll}
t_{x} & t_{y} & t_{z} & y t_{z} & -x t_{z} & \left(x t_{y}-y t_{x}\right)
\end{array}\right]^{\mathrm{T}} \mathrm{d} \phi
$$

where the angular position $\phi$ is defined in Fig. 3. Similarly, the base soil reaction vector $\mathbf{p}^{\text {base }}=$

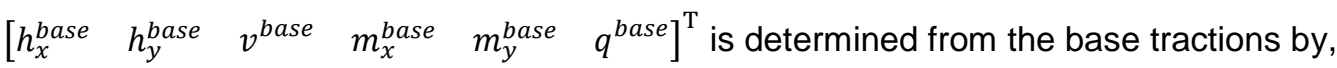

$$
\mathbf{p}^{\text {base }}=\int_{\text {Base }}\left[\begin{array}{llllll}
t_{x} & t_{y} & t_{z} & y t_{z} & -x t_{z} & \left(x t_{y}-y t_{x}\right)
\end{array}\right]^{\mathrm{T}} \mathrm{d} A
$$


where $\mathbf{d} \boldsymbol{A}$ is an element of area.

Equilibrium

An equilibrium equation for the caisson is established by virtual work as follows. Rigid body virtual displacements are imposed on the caisson via virtual global displacements $\delta \mathbf{U}$ applied at the RP. The corresponding local virtual displacements at an arbitrary point $(x, y, z)$ on the caisson skirt and base are $\delta \mathbf{s}=\left(\delta u_{x}, \delta u_{y}, \delta u_{z}\right)^{T}$. The local and global virtual displacements are related by,

$$
\delta \mathbf{s}=\left[\begin{array}{l}
\delta U_{x}+z \delta \Theta_{y}-y \delta \Theta_{z} \\
\delta U_{y}+x \delta \Theta_{z}-z \delta \Theta_{x} \\
\delta U_{z}+y \delta \Theta_{x}-x \delta \Theta_{y}
\end{array}\right]
$$

The virtual work done on the soil by the soil tractions acting on the caisson skirt is (see Fig 3),

$$
\delta W^{\text {skirt }}=\frac{D}{2} \int_{0}^{L} \int_{0}^{2 \pi}(\delta \mathbf{s})^{\mathrm{T}} \mathbf{t} \mathrm{d} \phi \mathrm{d} z
$$

On the basis of Equation 5 (applied to the virtual displacements in Equation 10) and Equation 8, this equation can be expressed in terms of the local cross section virtual displacements and skirt soil reactions as,

$$
\delta W^{\text {skirt }}=\int_{0}^{L}(\delta \mathbf{u})^{\mathrm{T}} \mathbf{p}^{\text {skirt }} \mathrm{d} z
$$

Similarly, the virtual work done on the soil by the soil tractions acting on the base cross section is,

$$
\delta W^{\text {base }}=\int_{\text {Base }}(\delta \boldsymbol{s})^{\mathrm{T}} \mathbf{t} \mathrm{d} A=\delta \mathbf{u}^{T} \mathbf{p}^{\text {base }}
$$

The total internal virtual work is $\delta W^{\text {int }}=\delta W^{\text {skirt }}+\delta W^{\text {base }}$. The total external virtual work $\delta W^{e x t}$ is the work done by $\mathbf{P}$ at RP. Equating the internal and external virtual work gives,

$$
\begin{gathered}
\delta W^{\text {ext }}=\delta W^{\text {int }} \\
\delta \mathbf{U}^{\mathrm{T}} \mathbf{P}=\int_{0}^{L} \delta \mathbf{u}^{\mathrm{T}} \mathbf{p}^{\text {skirt }} \mathrm{d} z+\delta \mathbf{u}^{\mathrm{T}} \mathbf{p}^{\text {base }}
\end{gathered}
$$

Substituting Equations 5 and 7 into Equation 15 gives, 


$$
\begin{aligned}
& \delta \mathbf{U}^{\mathrm{T}} \mathbf{P}=\int_{0}^{L}(\mathbf{J} \delta \mathbf{U})^{\mathrm{T}} \mathbf{p}^{\text {skirt }} d z+\left(\mathbf{J}^{\text {base }} \delta \mathbf{U}\right)^{\boldsymbol{T}} \boldsymbol{p}^{\text {base }} \\
& \delta \mathbf{U}^{\mathrm{T}}\left(\int_{0}^{\mathrm{L}} \mathbf{J}^{\mathrm{T}} \mathbf{p}^{\text {skirt }} \mathrm{d} z+\left(\mathbf{J}^{\text {base }}\right)^{\mathrm{T}} \mathbf{p}^{\text {base }}-\mathbf{P}\right)=0
\end{aligned}
$$

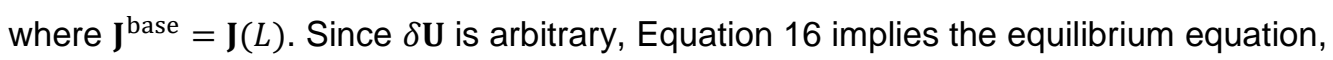

$$
\mathbf{P}=\int_{0}^{L} \mathbf{J}^{\mathrm{T}} \mathbf{p}^{\text {skirt }} \mathrm{d} z+\left(\mathbf{J}^{\text {base }}\right)^{\mathrm{T}} \mathbf{p}^{\text {base }}
$$

Equation 17 demonstrates that the current formulation reduces the original problem (specified in three spatial dimensions) is to a single dimension ( $z$ ).

\section{Local stiffness matrix}

By considering the symmetries in the problem, it can be demonstrated that the local stiffness matrix, $\mathbf{k}$, has the general form,

$$
\mathbf{k}=\left[\begin{array}{cccccc}
k_{\mathrm{h}} & 0 & 0 & 0 & -k_{\mathrm{ch}} & 0 \\
0 & k_{\mathrm{h}} & 0 & k_{\mathrm{ch}} & 0 & 0 \\
0 & 0 & k_{\mathrm{v}} & 0 & 0 & 0 \\
0 & k_{\mathrm{cm}} & 0 & k_{\mathrm{m}} & 0 & 0 \\
-k_{\mathrm{cm}} & 0 & 0 & 0 & k_{\mathrm{m}} & 0 \\
0 & 0 & 0 & 0 & 0 & k_{\mathrm{q}}
\end{array}\right]
$$

The general form of the stiffness matrix therefore has six independent coefficients. Analysis of the 3D finite element results has shown that if $\mathbf{k}$ is determined directly from the results of a 3D finite element calibration analysis, then symmetry of the local stiffness matrix is not guaranteed (i.e. the off-diagonal coefficients $k_{c h}$ and $k_{c m}$ are not necessarily equal). There is also no guarantee that the matrix is positive definite. This general lack of symmetry and positive definiteness is a consequence of the Winkler concept, in which spatial coupling within the soil is excluded.

It is a feature of OxCaisson that the global stiffness matrices (i.e. Equation 2) determined by the model are guaranteed to be both symmetric and positive definite; this ensures consistency with the laws of thermodynamics (e.g. Ottosen \& Ristinmaa 2005); matrices with these characteristics are referred to in this paper as 'thermodynamically consistent'. If the global stiffness matrices are not thermodynamically consistent, unrealistic results may be obtained, such as non-unique solutions in a static linear elastic analysis, or negative and/or imaginary natural frequencies in an eigenvalue analysis. The approach adopted to ensure this outcome (sufficient but not necessary) is to constrain the local stiffness matrices to be symmetric and positive definite at all locations on the skirt and also at the base (see Appendix). This procedure 
requires certain adjustments to one of the local coupling stiffness coefficients determined from the 3D calibration analyses.

\section{Computing the global stiffness matrix}

For a rigid caisson, the global stiffness matrix is determined from the local stiffness matrices (on the basis of the equilibrium equation in Equation 17) by,

$$
\mathbf{K}=\int_{0}^{L} \mathbf{J}^{\mathrm{T}} \mathbf{k}^{\text {skirt }} \mathbf{J} \mathrm{d} z+\left(\mathbf{J}^{\text {base }}\right)^{\mathrm{T}} \mathbf{k}^{\text {base }} \mathbf{J}^{\text {base }}
$$

The integration is conducted numerically.

An alternative form of the model, incorporating a flexible skirt, has also been formulated. This employs a one dimensional (1D) finite element model in which the skirt is represented as a line mesh of 2-noded frame elements. The frame elements represent torsional and axial strains in the caisson skirt using linear Lagrangian shape functions. Lateral displacements and rotations due to bending and shear are modelled using Timoshenko beam theory (employing the five degrees-of-freedom Timoshenko beam element formulation in Astley 1992).

The current model is concerned with suction caissons that have relatively small values of $L / D$. In this case, it is open to question whether Timoshenko beam theory is sufficient to provide a robust model for the deformations that occur in the skirt. The use of Timoshenko theory (rather than higher order beam theories) is preferred in the current context, however, to maintain the overall simplicity of the model. It is demonstrated in a subsequent section of the paper that the Timoshenko beam approximation on OxCaisson provides values of the global stiffness coefficient that compare well with 3D finite element analysis, therefore supporting the proposed formulation.

\section{FINITE ELEMENT CALIBRATION CALCULATIONS}

\section{Specification of the calculations}

3D finite element calibration analyses have been conducted for suction caissons with the configuration in Fig 1. Six shear modulus profiles (employing the stiffness profile in Equation 1), corresponding to $\alpha=0,0.2,0.4,0.6,0.8,1$, are considered, where $\alpha=0$ represents the homogeneous soil case. For each case, six values of Poisson's ratios $(v=$ $0,0.1,0.2,0.3,0.4,0.49)$ were analysed. Caissons with embedment ratios $L / D=$ $0,0.125,0.25,0.5,1,2$ and skirt thickness $d^{\text {skirt }} / D=0.005$ were considered. Other values of skirt thickness were analysed ( $d^{\text {skirt }} / D=0.001,0.01$ ) but the influence of skirt thickness was found to have a negligible effect on the results; the results presented below therefore all relate to $d^{\text {skirt }} / D=0.005$. The $L / D=0$ case represents a rigid, circular surface foundation. 
The finite element calibration analyses were conducted using the commercial finite element software Abaqus v6.13 (Dassault Systèmes 2014). First-order, fully-integrated, linear, brick elements C3D8 (C3D8H for $v=0.49$ ) were employed for the soil. These elements were also used to represent the caisson. These elements were found to be adequate for the current work as comparisons with initial analyses using higher-order alternatives (C3D20 or C3D20H) showed insignificant differences. The mesh domain was set to $100 \mathrm{D}$ for both width and depth; this was considered sufficiently large for boundary effects to be negligible. The maximum change in the global stiffness matrix components was $0.2 \%$ when the domain was increased from $100 \mathrm{D}$ to $200 \mathrm{D}$. Displacements were fixed in all directions at the bottom of the mesh and in the radial directions on its periphery. Mesh convergence analyses were carried out to determine an appropriate level of mesh refinement. The maximum change in the global stiffness matrix components was $0.3 \%$ when the number of elements was increased from 80,000 to 160,000 . An example finite element mesh is shown in Fig. 4.

Displacements of the caisson were imposed in the model using rigid body constraints. Contact breaking between the soil and caisson was prevented using tie constraints at the soil-caisson interface. Due to symmetry, only four independent prescribed displacement modes are required to compute the behaviour of the foundation for six degrees-of-freedom loading; the prescribed displacement modes employed in the analyses are listed in Table 1.

To validate the finite element model, computed values of the global stiffness coefficients in Equation 2 were compared with previous results in Doherty et al. (2005). Examples of the comparison of normalised forms of the global stiffness coefficients are shown in Table 2, for $L / D=0.5$ and $\alpha=0$. A close agreement is apparent between the two data sets, with the maximum deviation being $3.2 \%$; this supports the suitability of the 3D finite element calibration procedures employed in the current work.

\section{Determining the local stiffness matrices}

To determine the local stiffness coefficients from the finite element results, the contact nodal forces of the soil elements adjacent to the caisson are resolved into tractions in each of the $(x, y, z)$ directions. For the skirt, the relevant nodal forces are determined from rings of soil elements in contact with the skirt exterior (Fig. 5). For the base soil reactions, the relevant nodal forces are determined from the soil elements directly below the caisson base (Fig. 5). Local soil reaction vectors $\mathbf{p}^{\text {skirt }}$ and $\mathbf{p}^{\text {base }}$ are computed from the tractions using Equations 8 and 9.

Stiffness relationships between the local soil reactions and the global displacements are initially determined directly from the calibration analyses in $(6 \times 6)$ matrix form as $\frac{\partial \mathbf{p}^{\text {skirt }}}{\partial \mathbf{U}}$ for the skirt and $\frac{\partial \mathbf{p}^{\text {base }}}{\partial \mathbf{U}}$ for the base. The local stiffness matrices for the skirt are then obtained from, 


$$
\begin{aligned}
\frac{\partial \mathbf{p}^{\text {skirt }}}{\partial \mathbf{U}} & =\frac{\partial \mathbf{p}^{\text {skirt }}}{\partial \mathbf{u}} \frac{\partial \mathbf{u}}{\partial \mathbf{U}}=\frac{\partial \mathbf{p}^{\text {skirt }}}{\partial \boldsymbol{u}} \mathbf{J}(z) \\
\mathbf{k}^{\text {skirt }} & =\frac{\partial \mathbf{p}^{\text {skirt }}}{\partial \mathbf{u}}=\frac{\partial \mathbf{p}^{\text {skirt }}}{\partial \mathbf{U}} \mathbf{J}(z)^{-\mathbf{1}}
\end{aligned}
$$

Similarly, the local stiffness matrix for the base is determined from,

$$
\mathbf{k}^{\text {base }}=\frac{\partial \mathbf{p}^{\text {base }}}{\partial \mathbf{U}}\left(\mathbf{J}^{\text {base }}\right)^{-1}
$$

The local stiffness coefficients are presented below, employing the dimensionless forms that are defined in the left column of Table 3 (for the skirt) and the left column of Table 5 (for the base). For the skirt stiffness coefficients, the dimensionless forms employ the local shear modulus $G$. The base coefficients, however, are normalised using $G_{b}$, which is the shear modulus at a depth of $D / 2$ below the caisson base; the local shear modulus is not suitable for normalising the base soil reactions, as it is zero-valued for $L / D=0$ and $\alpha>0$.

Fig. 6 shows normalised local skirt and base stiffness coefficients, for the example case of $\alpha=$ 0 and three embedment ratios $(L / D=0.5,1,2)$. Fig. $6 \mathrm{e}$, $\mathrm{f}$ indicates that the local stiffness matrices determined from the $3 \mathrm{D}$ calibration analysis are, in general, non-symmetric (i.e. $k_{\mathrm{ch}}^{\text {skirt }} \neq k_{\mathrm{cm}}^{\text {skirt }}$ and $\left.k_{\mathrm{ch}}^{\text {base }} \neq k_{\mathrm{cm}}^{\text {base }}\right)$. Similar lack of symmetry in the local stiffness matrices was observed in the other cases considered. As described earlier, the OxCaisson model requires that the local stiffness matrix employed in the model is symmetric and positive definite. Special procedures, described in a subsequent section, are therefore employed to develop symmetric and positive definite local stiffness matrices from the non-symmetrical stiffness data determined from the calibration analyses.

\section{LOCAL SOIL STIFFNESS FUNCTIONS}

To represent the local soil stiffness behaviour $\mathbf{p}=\mathbf{k u}$ in the OxCaisson model, appropriate functional forms (referred to as 'local soil stiffness functions') are developed in terms of the normalised forms. The diagonal and off-diagonal components of the local stiffness matrices are considered separately, as described below.

\section{Diagonal components of the local stiffness matrix}

The data in Fig. 6 indicate a tendency for the normalised local skirt stiffness coefficients on the diagonal of the local stiffness matrix $\left(\bar{k}_{v}, \bar{k}_{q}, \bar{k}_{h}, \bar{k}_{m}\right)$ to increase slightly with depth, with a higher rate of stiffness increase close to the base. Similar patterns were observed in the other calibration data. For simplicity, it was decided to adopt local soil stiffness functions in which these normalised local stiffness coefficients are constant with depth; values of the normalised stiffness coefficients were computed for each calibration case by least squares regression. The 
values of the stiffness coefficients determined in this way depend on $L / D, \alpha$ and $v$. After some experimentation, it was found that the normalised stiffness coefficients could be accurately represented by a parametric equation of the form,

$$
\bar{k}^{\text {skirt }}=\left(a_{1}+a_{2} v\right)\left(1-\frac{\left(a_{3}+a_{4} v\right) \frac{L}{D}}{\left(a_{5}+a_{6} v\right) \frac{L}{D}+1}\right)
$$

where $a_{i}(i=1,2,3,4,5,6)$ are parameters determined separately for each normalised stiffness coefficient. Values of the parameters determined by least squares regression over the whole data set are listed in Table 3. Values of the normalised stiffness parameters determined by Equation 22 are shown in Fig. 7 for the example case of $v=0.2$. A close fit between the calibration data and the parametric model is evident, with the average coefficient of determination $\mathrm{R}^{2}$ for the four fits in Fig. 7 being 0.999 . A similarly close match was obtained for all other cases considered.

The normalised base stiffness coefficients determined from the calibration analyses were found to be closely represented by the parametric equation,

$$
\bar{k}_{\text {base }}=k_{0}+\left(a_{1}+\frac{a_{2}}{1-v}\right)\left(1-\frac{1}{a_{3} \frac{L}{D}+1}\right)
$$

The term $k_{0}$ in Equation 23 is the normalised stiffness coefficient for a rough, rigid, circular surface foundation and $a_{i}(i=1,2,3)$ are parameters. Polynomial functions of Poisson's ratio and $\alpha$ are employed for $k_{0}$ such that the function reduces to standard cases for homogeneous soil (Table 4) when $\alpha=0$. Values of $a_{i}$ and the parameters required to calibrate $k_{0}$ were determined by least squares regression over the whole data set; the resulting parameters are listed in Table 5.

Comparisons between the data extracted from the 3D finite element calibration analyses and the parametric model are shown in Fig. 8 for the example case $v=0.2$. A close fit between the data and the parametric model is apparent, with the average $R^{2}$ for the four fits in Fig. 8 being 0.934 .

Off-diagonal components of the local stiffness matrix

The local stiffness matrices incorporated in the OxCaisson model are required to be positive definite with the symmetric form, 


$$
\mathbf{k}=\left[\begin{array}{cccccc}
k_{\mathrm{h}} & 0 & 0 & 0 & -k_{\mathrm{c}} & 0 \\
0 & k_{\mathrm{h}} & 0 & k_{\mathrm{c}} & 0 & 0 \\
0 & 0 & k_{\mathrm{v}} & 0 & 0 & 0 \\
0 & k_{\mathrm{c}} & 0 & k_{\mathrm{m}} & 0 & 0 \\
-k_{\mathrm{c}} & 0 & 0 & 0 & k_{\mathrm{m}} & 0 \\
0 & 0 & 0 & 0 & 0 & k_{\mathrm{q}}
\end{array}\right]
$$

To develop a local stiffness matrix from the (non-symmetrical) form determined directly from the $3 \mathrm{D}$ calibration analyses, three possible straightforward choices exist to define $k_{c}$; (i), $k_{c}$ is set equal to the value of $k_{c m}$ determined from the $3 \mathrm{D}$ calibration analyses, $\left(k_{c} \equiv k_{c m}\right)$; (ii), $k_{c} \equiv k_{c h}$; or (iii) $k_{c} \equiv \frac{1}{2}\left(k_{c m}+k_{c h}\right)$. On the basis of Sylvester's criterion for positive definite matrices (i.e. the determinants associated with all upper-left submatrices are positive), positive definiteness of the matrix requires that,

$$
\begin{gathered}
k_{h}>0, k_{v}>0, k_{m}>0, k_{q}>0 \\
k_{h} k_{m}-k_{c}{ }^{2}>0
\end{gathered}
$$

The conditions in Equation 25 are satisfied by the current model, at least in the parameter space explored in this paper. After evaluating the three possible options outlined above, only option (i) $k_{c} \equiv k_{c m}$ was found to satisfy Equation 26 in all cases. Option (i) was therefore adopted to develop the local stiffness matrices, for both the skirt and the base, in the OxCaisson model. To ensure that the local stiffness matrices are symmetric and positive definite, the acceptable ranges for the Poisson's ratio and embedment ratio are $0 \leq v<0.5$ and $0 \leq L / D \leq 2$.

Incorporating the artificially-symmetric local stiffness matrix into the model means that a correction needs to be applied to ensure that the adjustments made to the local stiffness matrix (to make it symmetric) do not propagate errors to the calculation of the global stiffness matrix. For the rigid caisson form of the model (Equation 19), the local modifications cause variations in the global stiffness terms $K_{C H}$ and $K_{M}$. The variation in $K_{C H}$ was found to be small (less than $2 \%$ deviation) and this is neglected in the current model. However, the difference, $\Delta K_{M}$, in the computation of $K_{M}$ was found to be significant. For example, if left uncorrected, the model prediction of $K_{M}$ for the typical case of $v=0.2, L / D=1, \alpha=0$ would be $30 \%$ lower than the value of $K_{M}$ determined from the corresponding $3 \mathrm{D}$ finite element model. On the basis of the rigid caisson model in Equation 19,

$$
\Delta K_{M}=\int_{0}^{L}\left(k_{c h}^{\text {skirt }}-k_{c}^{\text {skirt }}\right)(-z) d z+\left(k_{c h}^{\text {base }}-k_{c}^{\text {base }}\right)(-L)
$$

To correct the model, the stiffness difference $\Delta K_{M}$, is applied uniformly along the skirt length by means of an additional artificial local rotational stiffness coefficient, $\Delta k_{m}^{\text {skirt }}$, determined from 
$\Delta K_{M}=\int_{0}^{L} \Delta k_{m}^{\text {skirt }} d z$. The value of the local rotational stiffness $\left(k_{m}^{\text {skirt }}\right)^{\text {model }}$ employed in the OxCaisson model is therefore,

$$
\left(k_{m}^{\text {skirt }}\right)^{\text {model }}=k_{m}^{\text {skirt }}+\Delta k_{m}^{\text {skirt }}
$$

where $k_{m}^{\text {skirt }}$ is the rotational stiffness coefficient determined from the parametric model (as specified in Table 3). Least squares regression was conducted to determine the following approximation for $\Delta k_{m}^{\text {skirt }}$,

$$
\frac{\Delta k_{m}^{\text {skirt }}}{G D^{2}}=\left(0.94-0.0382 \alpha+0.0846 \alpha^{2}+\frac{0.21-0.286 \alpha}{1-v}\right) \frac{L}{D}+0.23+0.14 \alpha-0.0868 \alpha^{2}
$$

Fig. 9 shows an example comparison for $\alpha=0$ of the values of $\Delta k_{m}^{\text {skirt }}$ determined directly from the 3D finite element results and the values determined by Equation 29. This shows a close match between the numerical data and the assumed model, with the $\mathrm{R}^{2}$ of the fit being 0.999 ; a similarly close match was obtained for the other cases considered. It should be emphasised that $\Delta k_{m}^{\text {skirt }}$ is an artificial stiffness; it should not be interpreted beyond being a simple correction for $K_{M}$.

\section{EVALUATION OF THE OXCAISSON MODEL}

Fig. 10 compares the global stiffness coefficient predictions of OxCaisson (using Equation 19) with the corresponding 3D finite element results for $L / D=0.125,0.25,0.5,1,2, v=0.2$ and $\alpha=$ $0,0.5,1$. Note that $\alpha=0.5$ is a new test value, not included in the calibration set. To quantify the prediction errors, Table 6 shows the average percentage differences (APD) and root-meansquare percentage errors (RMSPE) of the global stiffness coefficient predictions in Fig. 10. It is evident from Table 6 that the OxCaisson predictions agree well with the 3D finite element computations for the homogeneous case $(\alpha=0)$, especially for $K_{V}, K_{Q}, K_{H}$. The maximum RMSPE is $6.41 \%$ for $K_{C}$. For the non-homogeneous cases $(\alpha=0.5,1)$, the overall agreement is still reasonable, although the maximum RMSPE increases to $12 \%$ for $K_{C}$. It can be observed that there is some under-prediction for $K_{M}$ and $K_{C}$ (i.e. negative values of APD). This is likely due to the OxCaisson computations for $K_{M}$ and $K_{C}$ being significantly influenced by $k_{h}^{\text {skirt }}$. The uniform-with-depth idealisation employed in the model excludes a significant moment contribution from the relatively large lateral soil reaction, apparent in the finite element results, that develop near the base of the caisson (e.g. Fig. 6c).

Application to suction caissons with a flexible skirt

Separate analyses have been conducted to investigate the extent to which the OxCaisson model, calibrated using the rigid caisson approach described above, is applicable when skirt flexibility is incorporated. The 1D finite element version of the OxCaisson model - which 
incorporates the effects of skirt flexibility - represents the caisson skirt with a line mesh of frame elements. Separate finite element analyses were conducted in which the rigid constraints imposed on the skirt were removed (although the rigid body constraints applied to the lid are retained). For these analyses, a single layer of second-order, fully-integrated, brick elements C3D20 was employed for the caisson skirt. The Young's modulus and Poisson's ratio for the skirt was set at $206 \mathrm{GPa}$ and 0.3 respectively, Separate OxCaisson analyses were conducted employing the 1D finite element version of the model (in which shear and bending in the skirts is represented by Timoshenko beam theory). The thin walled approximation was employed for the area and second moment of area of the caisson skirt. A shear factor of $\kappa=\frac{1+v}{2+v}$ (Hutchison 2001) was adopted.

Table 7 lists the ratios of the global stiffness coefficients for flexible and rigid caissons computed by the 3D finite element model for $L / D=0.125,0.25,0.5,1,2, v=0.2$ and $\alpha=0,0.5,1$. It is evident that there are significant differences between the flexible and rigid cases, especially for high values of $L / D$ and non-homogeneous soil $(\alpha>0)$. Thus, it is important that the skirt flexibility is considered when designing suction caissons. Fig. 10 compares the OxCaisson global stiffness coefficient predictions with those computed from the 3D finite element analyses; this shows generally good agreement. Table 6 also shows the APD and RMSPE calculations for the OxCaisson predictions, relative to the corresponding 3D finite element results, for the flexible skirt case. The OxCaisson predictions agree well with the 3D finite element computations for the cases listed in the table, with a maximum RMSPE of $6.77 \%$ for $K_{M}$.

\section{Application to short rigid monopiles}

Further exploratory analyses have been conducted using the 3D finite element model in which the lid is absent from the analysis. The model in this case represents a 'short' rigid monopile. Calculations were conducted by applying rigid body constraints to the monopile. Fig. 11 shows the computed global stiffness coefficients and the local stiffness coefficients for the skirt and base soil reactions of the monopile, relative to those of the caisson, for $\alpha=0$ (homogeneous soil).

Fig. 11 indicates that the presence of the rigid caisson lid has negligible influence on the global torsional and lateral stiffness coefficients for embedment ratios $0.125 \leq L / D \leq 2$, and for the global vertical, moment and coupling stiffness coefficients for $0.25 \leq L / D \leq 2$. As $L / D$ decreases from 0.25 , however, the global vertical, moment and coupling stiffness coefficients for the monopile decreases slightly relative to those of the corresponding caisson foundation. This tendency is consistent with previous finite element studies described by Efthymiou \& Gazetas (2018). It is evident from Fig. 11a, d, e that as $L / D$ decreases from 0.5 , the local stiffness coefficients for the skirt and base soil reactions for the monopile foundation increase 
and decrease respectively, relative to the caisson case. The caisson lid therefore appears to increase the load on the base at the expense of the skirt for $L / D<0.5$.

The apparent equivalence in caisson and short monopile performance for certain cases, as computed with the 3D finite element model, suggests that the current OxCaisson model could be employed for the analyses of monopiles with embedment ratios in the range $0.5 \leq L / D \leq 2$ (or $0.125 \leq L / D \leq 2$ for torsional and lateral stiffness).

\section{DISCUSSION}

The Winkler suction caisson model described in the paper - OxCaisson - provides a rapid analysis tool to assess the stiffness of suction caissons embedded in homogeneous and nonhomogeneous elastic soil. For example, using a computer with an Intel Xeon $3.60 \mathrm{GHz}$ processor (eight central processing units) with 16 GB RAM (random access memory), a single OxCaisson analysis usually takes less than a second, while its corresponding 3D finite element analysis usually takes approximately 5 minutes. The total run time for all of the 3D finite element analyses covered in this study is in the order of days, while it took only seconds to do the same with OxCaisson. The model is therefore highly suited to time-critical design tasks such as optimisation of large-scale offshore windfarm design.

Two forms of the model are proposed; (i) a rigid caisson model in which kinematic conditions are used to relate the local caisson displacements to the displacements at a specified reference point, and (ii) an alternative form, to incorporate the influence of skirt flexibility, which employs embedded frame finite elements. A principal intended application of the model is to formulate foundation models for incorporating in integrated analyses to assess the fundamental natural frequency of wind turbine support structures under ambient loading conditions. These natural frequency analyses are required to assess the high-cycle fatigue damage induced in the support structure by the many millions of relatively small-amplitude load cycles applied to it during its lifetime. For these small-amplitude load cycles, the linear elastic modelling approach considered in the current work provides a means of minimising the complexity of the model while also capturing the relevant aspects of soil behaviour. It is noted that the current model employs a fully-tied condition at the soil-foundation interface. This condition is considered appropriate for the small displacement loading envisaged in the fatigue assessment calculations referred to above. For higher levels of loading, the possibility of gapping between the caisson and the soil may need to be considered.

The elastic model employed in the current work does not incorporate the influence of soil drainage conditions on the performance of the caisson. For cases where the soil can be considered to be undrained or fully drained, appropriate values of the elastic soil parameters $(G, v)$ for incorporation in the model can be determined readily. In partial drainage cases (determined on the basis of the loading frequency, the soil permeability and the dimensions of 
the foundation), appropriate values of the elastic soil parameters for incorporation in the model may be estimated based on previous research (e.g. Damgaard et al. 2014).

The OxCaisson model represents the local soil-foundation interaction via a local coupled stiffness matrix; the local stiffness coefficients are determined via 3D finite element calibration calculations. To ensure thermodynamic consistency of the overall model, certain adjustments are required at the local level. Approximate analytical expressions are presented for the local stiffness coefficients in the calibration range $0 \leq v<0.5$ and $0 \leq L / D \leq 2,0 \leq \alpha<1$ (where $\alpha$ is the stiffness exponent employed in the depth varying shear modulus model). In spite of the approximations inherent in the OxCaisson approach, the rigid and flexible forms of the model have been found to agree well with the global stiffness predictions by the existing macroelement model for suction caisson foundations (Doherty et al. 2005). Differences between the predictions of the current model and Doherty et al. (2005) are most significant for the global rotational moment stiffness $K_{M}$. For the example case of $v=0.2, L / D=1, \alpha=0, d^{\text {skirt }} / D=$ 0.005 , differences between the current work and the data in Doherty et al. (2005) for $K_{M}$ amount to $4.8 \%$ and $7.4 \%$ for rigid and flexible caissons respectively. The OxCaisson model also conforms closely to the 3D finite element results presented in the current paper. The OxCaisson model is therefore able to approximate the calculations of relatively complex numerical modelling procedures, but at a fraction of the computational cost.

Consistent with previous work (e.g. Doherty et al. 2005), the current study highlights the significant influence that the flexibility of the skirts can have on the overall stiffness of the caisson. This differentiates the performance of suction caissons from solid caissons for which the foundation is typically regarded as entirely rigid. Although not included in the current study, previous work by Skau et al. (2019) has highlighted the potential influence of caisson lid flexibility on the vertical component of the foundation stiffness. A consideration of lid flexibility effects would require an analysis of plate bending effects in the lid. It is considered that these effects could be combined with the current model in an approximate way, although this has not been attempted in the current work.

The current model is calibrated for power law depth variations in the shear modulus; this is consistent with previous work (e.g. Doherty et al 2005). Although stiffness variations of this sort are regarded as a useful approximate representation of the characteristics of natural deposits, this approach may not be appropriate for cases where a suction caisson is embedded in soils with distinct layers with significant differences in stiffness. Additionally, it is noted that suction caisson foundations are commonly employed as foundations for jacket-type structures. In this application, three or four foundations are likely to be employed to support the jacket and interactions may occur between each foundation. The current modelling approach is based on the assumption that each foundation is independent; the possibility of interactions between nearby foundations is therefore excluded. 
A key feature of the flexible skirt form of the OxCaisson model is that it can be employed, straightforwardly, to analyse caissons with skirt thickness that varies with depth. More generally, the calibrated Winkler modelling approach described in the paper is capable of being extended to incorporate more complex aspects of behaviour such as soil plasticity and slip/gapping at the soil-foundation interface. Developments of the model to incorporate these effects will form the basis of future publications.

\section{CONCLUSION}

The objective of this study is to develop a computationally efficient Winkler model that can provide accurate estimates of the stiffness of a rigid or flexible suction caisson foundation in homogeneous and non-homogeneous linear elastic soil under the full six degrees-of-freedom loading. The proposed model, OxCaisson, comprises thermodynamically consistent soil reactions that have been calibrated against the local soil response data from 3D finite element analyses. Generalised formulations of the calibrated soil reactions have been derived for six degrees-of-freedom loading; this facilitates OxCaisson predictions of the stiffness of suction caissons of any dimensions and soil properties within the calibration space. The results indicate that OxCaisson can approximate the 3D finite element stiffness calculations well, but at a small fraction of the computational time. Although OxCaisson was calibrated using a rigid caisson in the 3D finite element analyses, it was found that the calibrated soil reactions were sufficiently decoupled from the caisson structural properties that they may also be applied to flexible caissons and 'short', rigid monopiles $(0.5 \leq L / D \leq 2)$.

\section{ACKNOWLEDGEMENTS}

The first author would like to acknowledge the generous support of Ørsted Wind Power for funding his DPhil studentship at the University of Oxford. Byrne is supported by the Royal Academy of Engineering under the Research Chairs and Senior Research Fellowships scheme. 


\section{APPENDIX}

\section{A positive definite symmetric local stiffness matrix guarantees a positive definite} symmetric global stiffness matrix

For linear elastic soil and a rigid caisson, the work done on the Winkler model is equal to the strain energy stored in the elastic soil reactions,

$$
\frac{1}{2} \mathbf{U}^{\mathrm{T}} \mathbf{P}=\frac{1}{2} \int_{0}^{L} \mathbf{u}^{\mathrm{T}} \mathbf{p} d z
$$

Incorporating the stiffness relationships $\mathbf{P}=\mathbf{K U}$ and $\mathbf{p}=\mathbf{k u}$ into Equation $\mathrm{A} 1$ gives,

$$
\mathbf{U}^{\mathrm{T}} \mathbf{K} \mathbf{U}=\int_{0}^{L} \mathbf{u}^{\mathrm{T}} \mathbf{k} \mathbf{u} d z
$$

If $\mathbf{k}$ is positive definite at all depths then (on the basis of the definition of a positive definite matrix), $\mathbf{u}^{\mathrm{T}} \mathbf{k} \mathbf{u}>0$ for all non-zero $\mathbf{u}$. This implies from Equation $\mathrm{A} 2$ that $\mathbf{U}^{\mathrm{T}} \mathbf{K U}>0$ for all nonzero $\mathbf{U}$, and $\mathbf{K}$ is therefore guaranteed to be positive definite.

For both a rigid or flexible caisson, a matrix $\mathbf{B}$ can be found such that $\mathbf{u}=\mathbf{B} \mathbf{U}$. Equation $\mathbf{A} 2$ gives:

$$
\mathbf{U}^{\mathrm{T}} \mathbf{K} \mathbf{U}=\mathbf{U}^{\mathrm{T}}\left(\int_{0}^{L} \mathbf{B}^{\mathrm{T}} \mathbf{k B} d z\right) \mathbf{U}
$$

If $\mathbf{k}$ is symmetric (i.e. $\mathbf{k}=\mathbf{k}^{T}$ ), the integrand $\mathbf{B}^{\mathrm{T}} \mathbf{k B}$ must also be symmetric, since $\left(\mathbf{B}^{\mathrm{T}} \mathbf{k B}\right)^{\mathrm{T}}=$ $\mathbf{B}^{\mathrm{T}} \mathbf{k}^{\mathrm{T}} \mathbf{B}=\mathbf{B}^{\mathrm{T}} \mathbf{k B}$. Given that $\mathbf{K}=\int_{0}^{L} \mathbf{B}^{\mathrm{T}} \mathbf{k B} d z$ and the sum of symmetric matrices is also symmetric, it follows that $\mathbf{K}$ is guaranteed to be symmetric. 


\section{REFERENCES}

API 2010. RP 1A-WSD - Recommended Practice for Planning, Designing and Constructing Fixed Offshore Platforms. Washington: American Petroleum Institute.

Arany, L., Bhattacharya, S., Macdonald, J.H.G., Hogan, S.J. 2016) Closed form solutions of Eigen frequency of monopile supported offshore wind turbines in deeper waters incorporating stiffness of substructure and SSI. Soil Dynamics and Earthquake Engineering, 83 18-32

Astley, R.J. 1992. Finite Elements in Solids and Structures: An Introduction. Chapman Hall.

Gazetas, H. (1943), 'Uber ausmittig belastete, starre Platten auf elastich-isotropem Untergrund', Archive of Applied Mechanics 14, 1-8.

Bhattacharya, S 2019 Design of foundations for offshore wind turbines. John Wiley

Borowicka, H. (1943), 'Uber ausmittig belastete, starre Platten auf elastich-isotropem Untergrund', Archive of Applied Mechanics 14, 1-8.

Byrne, B.W., Houlsby, G.T., Burd, H.J., Gavin, K.G., Igoe, D.J.P, Jardine, R.J., Martin, C.M., McAdam, R.A., Potts, D.M., Taborda, D.M.G. and Zdravković, L. (2019) PISA Design Model for Monopiles for Offshore Wind Turbines: Application to a Stiff Glacial Clay Till. Geotechnique doi.org/10.1680/jgeot.18.P.255

Byrne, B. W., \& Houlsby, G. T. (2003). Foundations for offshore wind turbines. Philosophical Transactions of the Royal Society of London. Series A: Mathematical, Physical and Engineering Sciences, 361(1813), 2909-2930.

Damgaard, M., Bayat, M., Andersen, L. V., \& Ibsen, L. B. (2014), Assessment of the dynamic behaviour of saturated soil subjected to cyclic loading from offshore monopile wind turbine foundations. Computers and Geotechnics, 61, 116-126.

Dassault Systèmes (2014), Abaqus user manual, Simula Corp., Providence, RI.

Doherty, J. P., Houlsby, G. T. \& Deeks, A. J. (2005), 'Stiffness of Flexible Caisson Foundations Embedded in Nonhomogeneous Elastic Soil', Journal of Geotechnical and Geoenvironmental Engineering 131, 1498-1508.

Doherty, P. \& Gavin, K. (2011) Laterally loaded monopile design for offshore wind farms.

Proceedings of the Institution of Civil Engineers-Energy 165(1):7-17.

DNV 2016. DNVGL-ST-0126 - Support structure for wind turbines. Oslo: Det Norske Veritas.

Efthymiou, G. \& Gazetas, G. (2018), Elastic Stiffnesses of a Rigid Suction Caisson and Its Cylindrical Sidewall Shell, Journal of Geotechnical and Geoenvironmental Engineering 145 (2), 06018014.

Gerolymos, N. \& Gazetas, G. (2006a), 'Winkler model for lateral response of rigid caisson foundations in linear soil', Soil Dynamics and Earthquake Engineering 26(5), 347-361.

Gerolymos, N., \& Gazetas, G. (2006b), Static and dynamic response of massive caisson foundations with soil and interface nonlinearities—validation and results. Soil Dynamics and Earthquake Engineering, 26(5), 377-394.

Hutchinson, J. R. (2001), 'Shear Coefficients for Timoshenko Beam Theory', Journal of Applied Mechanics 68(1), 87-92.

Jalbi, S., Shadlou, M., \& Bhattacharya, S. (2018). Impedance functions for rigid skirted caissons supporting offshore wind turbines. Ocean Engineering, 150, 21-35.

Kallehave, D., Byrne, B. W., LeBlanc Thilsted, C., \& Mikkelsen, K. K. (2015). Optimization of monopiles for offshore wind turbines. Philosophical Transactions of the Royal Society A: Mathematical, Physical and Engineering Sciences, 373(2035), 20140100.

Mindlin, R. D. (1949), 'Compliance of elastic bodies in contact', Journal of Applied Mechanics 16, 259-268.

Ottosen, N. S., \& Ristinmaa, M. (2005). The mechanics of constitutive modeling. Elsevier.

Poulos, H. G. \& Davis, E. H. (1974), Elastic solution for soil and rock mechanics, John Wiley \& Sons, New York.

Reissner, E. (1944), 'On the Theory of Elastic Plates', Journal of Mathematics and Physics 23, 184-191.

Skau, K. S., Jostad, H. P., Eiksund, G., \& Sturm, H. (2019), Modelling of soil-structure-interaction for flexible caissons for offshore wind turbines. Ocean Engineering, 171, 273-285.

Spence, D. A. (1968), 'Self Similar Solutions to Adhesive Contact Problems with Incremental Loading', Proceedings of the Royal Society of London. Series A. Mathematical and Physical Sciences 305(1480), 55-80.

Tsigginos, C., Gerolymos, N., Assimaki, D., \& Gazetas, G. (2008). Seismic response of bridge pier on rigid caisson foundation in soil stratum. Earthquake Engineering and Engineering Vibration, 7(1), 33. 
Varun, Assimaki, D. \& Gazetas, G. (2009), 'A simplified model for lateral response of large diameter caisson foundations-Linear elastic formulation', Soil Dynamics and Earthquake Engineering 29(2), 268-291.

Versteijlen, W. G., de Oliveira Barbosa, J. M., van Dalen, K. N., \& Metrikine, A. V. (2018). Dynamic soil stiffness for foundation piles: Capturing 3D continuum effects in an effective, non-local 1D model. International Journal of Solids and Structures, 134, 272-282.

Winkler, E. (1867), Die Lehre von der Elastizitat und Festigkeit, Dominicus, Prague. 
Table 1. Displacement boundary conditions applied to the caisson at the RP (see Fig. 1a) in the $3 \mathrm{D}$ finite element analysis to determine the global stiffness coefficients. The value of $u_{0}$ is arbitrary

\begin{tabular}{l|cccccc}
\hline & $U_{x} / D$ & $U_{y} / D$ & $U_{z} / D$ & $\Theta_{x}$ & $\Theta_{y}$ & $\Theta_{z}$ \\
\hline Rigid Axial Translation & 0 & 0 & $u_{0}$ & 0 & 0 & 0 \\
Rigid Lateral & 0 & $u_{0}$ & 0 & 0 & 0 & 0 \\
$\begin{array}{l}\text { Translation } \\
\text { Rigid Rotation }\end{array}$ & 0 & 0 & 0 & $u_{0}$ & 0 & 0 \\
Rigid Torsion & 0 & 0 & 0 & 0 & 0 & $u_{0}$ \\
\hline
\end{tabular}

Table 2. Normalised global stiffness coefficients for compressible $(v=0.2)$ and nearly incompressible $(v=0.49)$ homogeneous linear elastic soil for a caisson with $L=0.5 D$.

Comparison of the results of 3D finite element analysis with data from Doherty et al. (2005).

\begin{tabular}{l|cccc}
\hline $\begin{array}{l}\text { Normalised } \\
\text { stiffness } \\
\text { coefficient }\end{array}$ & $v$ & $\begin{array}{c}\text { Doherty et al. } \\
(2005)\end{array}$ & $\begin{array}{c}\text { 3D finite element } \\
\text { analysis }\end{array}$ & Deviation (\%) \\
\hline$K_{V} / G D$ & 0.2 & 3.88 & 3.94 & 1.81 \\
$K_{Q} / G D^{3}$ & 0.2 & 2.43 & 2.45 & 0.82 \\
$K_{H} / G D$ & 0.2 & 4.55 & 4.66 & 2.42 \\
$K_{M} / G D^{3}$ & 0.2 & 2.1 & 2.14 & 1.9 \\
$K_{C} / G D^{2}$ & 0.2 & -1.58 & -1.63 & 3.16 \\
\hline$K_{V} / G D$ & 0.49 & 5.39 & 5.43 & 0.74 \\
$K_{Q} / G D^{3}$ & 0.49 & 2.43 & 2.45 & 0.82 \\
$K_{H} / G D$ & 0.49 & 5.45 & 5.56 & 2.02 \\
$K_{M} / G D^{3}$ & 0.49 & 2.5 & 2.42 & 3.2 \\
$K_{C} / G D^{2}$ & 0.49 & -1.73 & -1.73 & 0 \\
\hline
\end{tabular}


Table 3. Dimensionless forms adopted for the normalised local skirt soil stiffness coefficients (left column) where $G$ is the local value of shear modulus. Parameters for the skirt local stiffness coefficients for incorporation in Equation 22 (right column). Note that a correction $\Delta k_{m}^{\text {skirt }}$ (defined in Equation 29) needs to be added to $k_{m}^{\text {skirt }}$ to obtain the value of $\left(k_{m}^{\text {skirt }}\right)^{\text {model }}$ incorporated in OxCaisson, as per Equation 28.

\begin{tabular}{|c|c|}
\hline Normalised local stiffness coefficient & Soil stiffness function parameters \\
\hline $\bar{k}_{v}^{\text {skirt }}=\frac{k_{v}^{\text {skirt }}}{G}$ & $\begin{array}{l}a_{1}=10.8+12 \alpha+60 \alpha^{2} \\
a_{2}=14.4+56.5 \alpha+78 \alpha^{2} \\
a_{3}=4.2+6.83 \alpha+11.5 \alpha^{2} \\
a_{4}=5.2+11.2 \alpha-13.2 \alpha^{2} \\
a_{5}=5+6.68 \alpha+11.3 \alpha^{2} \\
a_{6}=5.8+10 \alpha-12 \alpha^{2}\end{array}$ \\
\hline $\bar{k}_{q}^{\text {skirt }}=\frac{k_{q}^{\text {skirt }}}{G D^{2}}$ & $\begin{array}{l}a_{1}=10.7+9.6 \alpha+17.5 \alpha^{2} \\
a_{2}=0 \\
a_{3}=10.4+16 \alpha+14.9 \alpha^{2} \\
a_{4}=0 \\
a_{5}=14.9+15.5 \alpha+14.6 \alpha^{2} \\
a_{6}=0\end{array}$ \\
\hline $\bar{k}_{h}^{\text {skirt }}=\frac{k_{h}^{\text {skirt }}}{G}$ & $\begin{array}{l}a_{1}=23.3+21.6 \alpha+124 \alpha^{2} \\
a_{2}=7.6+16.6 \alpha-7.46 \alpha^{2} \\
a_{3}=10.5+16.7 \alpha+25.6 \alpha^{2} \\
a_{4}=-8.9-15.5 \alpha-27.2 \alpha^{2} \\
a_{5}=12.2+16.4 \alpha+25.5 \alpha^{2} \\
a_{6}=-10.5-15.5 \alpha-26.8 \alpha^{2}\end{array}$ \\
\hline $\bar{k}_{m}^{\text {skirt }}=\frac{k_{m}^{\text {skirt }}}{G D^{2}}$ & $\begin{array}{l}a_{1}=3.8+6.58 \alpha+7.2 \alpha^{2} \\
a_{2}=1.6+0.341 \alpha+5.79 \alpha^{2} \\
a_{3}=9.55+24 \alpha+5.2 \alpha^{2} \\
a_{4}=-3-36.8 \alpha-2.81 \alpha^{2} \\
a_{5}=13.4+22.8 \alpha+5.16 \alpha^{2} \\
a_{6}=-6.8-38.9 \alpha\end{array}$ \\
\hline $\bar{k}_{c}^{\text {skirt }}=\frac{k_{c}^{\text {skirt }}}{G D}$ & $\begin{array}{l}a_{1}=-2.4-6.33 \alpha-5.52 \alpha^{2} \\
a_{2}=8.8+18.2 \alpha+78.1 \alpha^{2} \\
a_{3}=21+45.9 \alpha+45.2 \alpha^{2} \\
a_{4}=-27.4-52.6 \alpha-69 \alpha^{2} \\
a_{5}=21+46.7 \alpha+45.2 \alpha^{2} \\
a_{6}=-26.5-53.8 \alpha-69.8 \alpha^{2}\end{array}$ \\
\hline
\end{tabular}


Table 4. Normalised global stiffness coefficients for a rough, rigid, circular surface foundation (except for $K_{M}$ which is for the smooth case) on a homogeneous elastic half-space with shear modulus $G$. All the stiffness solutions are analytical solutions, except for $K_{C}$, which is approximated from the current 3D finite element model. Most of the analytical solutions are conveniently summarised in Poulos \& Davis (1974).

\begin{tabular}{c|c|c}
\hline $\begin{array}{l}\text { Normalised global } \\
\text { stiffness } \\
\text { coefficient }\end{array}$ & Formula & Source \\
\hline$K_{V} / G D$ & $\frac{2 \ln (3-4 v)}{1-2 v}$ & Spence (1968) \\
$K_{Q} / G D^{3}$ & $\frac{2}{3}$ & Reissner (1944) \\
$K_{H} / G D$ & $\frac{4}{2-v}$ & Mindlin (1949) \\
$K_{M} / G D^{3}$ & $\frac{1}{3(1-v)}$ & Borowicka (1943) \\
$K_{C} / G D^{2}$ & $\frac{0.185}{1-v}-0.37$ & 3D finite element results (this study) \\
\hline
\end{tabular}


Table 5. Dimensionless forms adopted for the normalised base soil stiffness coefficients (left column) where $G_{b}$ is the shear modulus at a distance $D / 2$ below the base. Parameters for the base local stiffness coefficients for incorporation in Equation 23 (right column).

\begin{tabular}{|c|c|}
\hline $\begin{array}{l}\text { Normalised local } \\
\text { stiffness coefficient }\end{array}$ & Base soil stiffness function parameters \\
\hline $\bar{k}_{v}^{\text {base }}=\frac{k_{v}^{\text {base }}}{G_{b} D}$ & $\begin{aligned} k_{0}= & \frac{2 \ln (3-4 v)}{1-2 v}\left(1+\left(4.32 v^{2}-0.167 v-0.533\right) \alpha\right. \\
& \left.\quad+(-1.15 v-0.236) \alpha^{2}\right) \\
a_{1}= & -0.612+7.74 \alpha-5.78 \alpha^{2} \\
a_{2}= & -0.715-4 \alpha+4.7 \alpha^{2} \\
a_{3}= & 5.85-21.3 \alpha+26.6 \alpha^{2}\end{aligned}$ \\
\hline $\bar{k}_{q}^{\text {base }}=\frac{k_{q}^{\text {base }}}{G_{b} D^{3}}$ & $\begin{array}{l}k_{0}=\frac{2}{3}\left(1-1.94 \alpha+1.01 \alpha^{2}\right) \\
a_{1}=-0.289+1.27 \alpha-0.655 \alpha^{2} \\
a_{2}=0 \\
a_{3}=28.2-72.6 \alpha+49.5 \alpha^{2}\end{array}$ \\
\hline $\bar{k}_{h}^{\text {base }}=\frac{k_{h}^{\text {base }}}{G_{b} D}$ & $\begin{array}{l}k_{0}=\frac{4}{2-v}\left(1+(-0.156 v-1.26) \alpha+(0.122 v+0.37) \alpha^{2}\right) \\
a_{1}=-0.453+1.63 \alpha-0.467 \alpha^{2} \\
a_{2}=-0.646+1.18 \alpha-0.35 \alpha^{2} \\
a_{3}=12-3.8 \alpha\end{array}$ \\
\hline $\bar{k}_{m}^{\text {base }}=\frac{k_{m}^{\text {base }}}{G_{b} D^{3}}$ & $\begin{aligned} k_{0}= & \frac{1}{3(1-v)}\left(1+\left(3.57 v^{2}-0.312 v-1.59\right) \alpha\right. \\
& \left.\quad+\left(-2.08 v^{2}-0.113 v+0.682\right) \alpha^{2}\right) \\
a_{1}= & 0.01+0.607 \alpha-0.434 \alpha^{2} \\
a_{2}= & -0.15-0.0211 \alpha+0.194 \alpha^{2} \\
a_{3}= & 12-7.88 \alpha\end{aligned}$ \\
\hline $\bar{k}_{c}^{\text {base }}=\frac{k_{c}^{\text {base }}}{G_{b} D^{2}}$ & 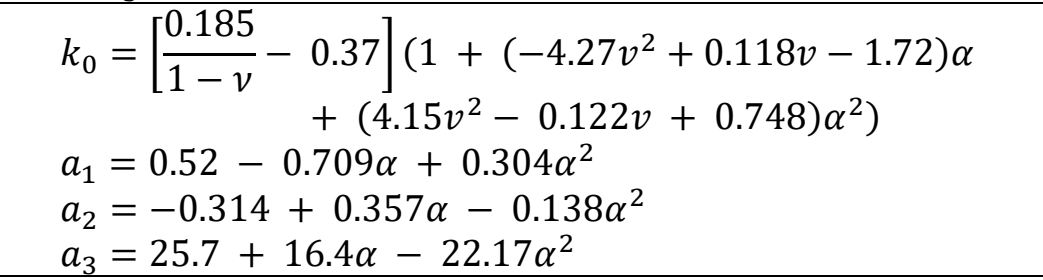 \\
\hline
\end{tabular}


Table 6. Average percentage difference (APD) and root mean square percentage error (RMSPE) of the global stiffness coefficients computed by OxCaisson relative to the 3D finite element results for rigid and flexible forms of the model (for $L / D=0.125,0.25,0.5,1,2, v=0.2$ and $\alpha=0,0.5,1$.). The APD is computed as $\frac{1}{n} \sum_{i=1}^{n} \epsilon_{i}$ and the RMSPE is computed as $\sqrt{\frac{1}{n} \sum_{i=1}^{n} \epsilon_{i}{ }^{2}}$ , where $n$ is number of data points, $\epsilon_{i}=100\left(\frac{K^{\text {pred. }(i)}}{K^{3 D F E}(i)}-1\right)$ is the relative percentage difference, and $K^{\text {pred. (i) }}$ and $K^{3 D F E ~(i)}$ are the global stiffness coefficients computed by OxCaisson and the $3 \mathrm{D}$ finite element model respectively.

\begin{tabular}{c|cc|cc|cc}
\hline \multirow{2}{*}{ Stiffness } & \multicolumn{2}{|c|}{$\alpha=0$} & \multicolumn{2}{c|}{$\alpha=0.5$} & \multicolumn{2}{c}{$\alpha=1$} \\
\cline { 2 - 7 } & $\begin{array}{c}\text { APD } \\
(\%)\end{array}$ & $\begin{array}{c}\text { RMSPE } \\
(\%)\end{array}$ & $\begin{array}{c}\text { APD } \\
(\%)\end{array}$ & $\begin{array}{c}\text { RMSPE } \\
(\%)\end{array}$ & $\begin{array}{c}\text { APD } \\
(\%)\end{array}$ & $\begin{array}{c}\text { RMSPE } \\
(\%)\end{array}$ \\
\hline$K_{V}^{\text {rigid }} / K_{V}^{3 D F E}$ & 0.95 & 1.51 & 0.26 & 0.94 & -4.42 & 5.95 \\
$K_{Q}^{\text {rigid }} / K_{Q}^{3 D F E}$ & 0.42 & 0.50 & -4.00 & 4.04 & -0.75 & 5.87 \\
$K_{H}^{\text {rigid }} / K_{H}^{3 D F E}$ & 1.18 & 2.53 & -5.24 & 5.96 & -5.08 & 6.40 \\
$K_{M}^{\text {rigid }} / K_{M}^{3 D F E}$ & -4.08 & 4.86 & -9.21 & 9.58 & -11.8 & 11.9 \\
$K_{C}^{\text {rigid }} / K_{C}^{3 D F E}$ & -6.14 & 6.41 & -11.7 & 12.0 & -10.4 & 11.3 \\
\hline$K_{V}^{\text {flexible }} / K_{V}^{3 D F E}$ & 0.95 & 1.48 & -0.24 & 0.80 & -4.62 & 6.08 \\
$K_{Q}^{\text {flexible }} / K_{Q}^{3 D F E}$ & 0.75 & 0.97 & -2.97 & 3.32 & 0.56 & 4.77 \\
$K_{H}^{\text {flexible }} / K_{H}^{3 D F E}$ & 3.61 & 3.89 & -1.00 & 2.43 & 0.34 & 2.78 \\
$K_{M}^{\text {flexible }} / K_{M}^{3 \text { SDFE }}$ & 5.33 & 6.77 & -0.65 & 4.60 & -3.42 & 6.54 \\
$K_{C}^{\text {flexible }} / K_{C}^{3 \text { DFFE }}$ & 4.22 & 4.63 & -1.81 & 3.76 & -0.372 & 3.10 \\
\hline
\end{tabular}


Table 7. Ratios of the global stiffness coefficients for a flexible caisson relative to those of a rigid caisson, as computed by the 3D finite element model for $v=0.2$ and $\alpha=0,0.5,1$.

\begin{tabular}{|c|c|c|c|c|c|c|}
\hline \multirow[t]{2}{*}{$\alpha$} & \multirow[t]{2}{*}{ Stiffness } & \multicolumn{5}{|c|}{$L / D$} \\
\hline & & 0.125 & 0.25 & 0.5 & 1 & 2 \\
\hline \multirow[t]{6}{*}{0} & $K_{V}^{\text {flexible }}$ & & & & & \\
\hline & $\begin{array}{l}/ K_{V}^{\text {rigid }} \\
K_{Q}^{\text {flexible }}\end{array}$ & 1.00 & 1.00 & 0.99 & 0.97 & 0.93 \\
\hline & $\begin{array}{l}/ K_{Q}^{\text {rigid }} \\
K_{H}^{\text {flexible }}\end{array}$ & 0.99 & 0.98 & 0.94 & 0.83 & 0.62 \\
\hline & $\begin{array}{l}/ K_{H}^{\text {rigid }} \\
K_{M}^{\text {flexible }}\end{array}$ & 0.96 & 0.95 & 0.91 & 0.81 & 0.60 \\
\hline & $\begin{array}{l}/ K_{M}^{\text {rigid }} \\
K_{C}^{\text {flexible }}\end{array}$ & 0.98 & 0.94 & 0.87 & 0.68 & 0.31 \\
\hline & $/ K_{C}^{\text {rigid }}$ & 0.90 & 0.87 & 0.81 & 0.64 & 0.33 \\
\hline \multirow[t]{6}{*}{0.5} & $K_{V}^{\text {flexible }}$ & & & & & \\
\hline & $\begin{array}{l}/ K_{V}^{\text {rigid }} \\
K_{Q}^{\text {flexible }}\end{array}$ & 1.00 & 1.00 & 0.98 & 0.94 & 0.83 \\
\hline & $\begin{array}{l}/ K_{Q}^{\text {rigid }} \\
K_{H}^{\text {flexible }}\end{array}$ & 1.00 & 0.98 & 0.93 & 0.77 & 0.46 \\
\hline & $\begin{array}{l}/ K_{H}^{\text {rigid }} \\
K_{M}^{\text {flexible }}\end{array}$ & 0.95 & 0.93 & 0.88 & 0.70 & 0.41 \\
\hline & $\begin{array}{l}/ K_{M}^{\text {rigid }} \\
K_{C}^{\text {flexible }}\end{array}$ & 0.99 & 0.95 & 0.86 & 0.59 & 0.19 \\
\hline & $/ K_{C}^{\text {rigid }}$ & 0.91 & 0.88 & 0.80 & 0.56 & 0.20 \\
\hline \multirow[t]{6}{*}{1} & $K_{V}^{\text {flexible }}$ & & & & & \\
\hline & $\begin{array}{l}/ K_{V}^{\text {rigid }} \\
K_{Q}^{\text {flexible }}\end{array}$ & 1.00 & 0.99 & 0.98 & 0.90 & 0.69 \\
\hline & $\begin{array}{l}/ K_{Q}^{\text {rigid }} \\
K_{H}^{\text {flexible }}\end{array}$ & 1.00 & 0.99 & 0.93 & 0.71 & 0.31 \\
\hline & $\begin{array}{l}/ K_{H}^{\text {rigid }} \\
K_{M}^{\text {flexible }}\end{array}$ & 0.95 & 0.93 & 0.85 & 0.59 & 0.26 \\
\hline & $\begin{array}{l}/ K_{M}^{\text {rigid }} \\
K_{C}^{\text {flexible }}\end{array}$ & 0.99 & 0.96 & 0.85 & 0.50 & 0.10 \\
\hline & $/ K_{C}^{\text {rigid }}$ & 0.93 & 0.89 & 0.78 & 0.46 & 0.12 \\
\hline
\end{tabular}




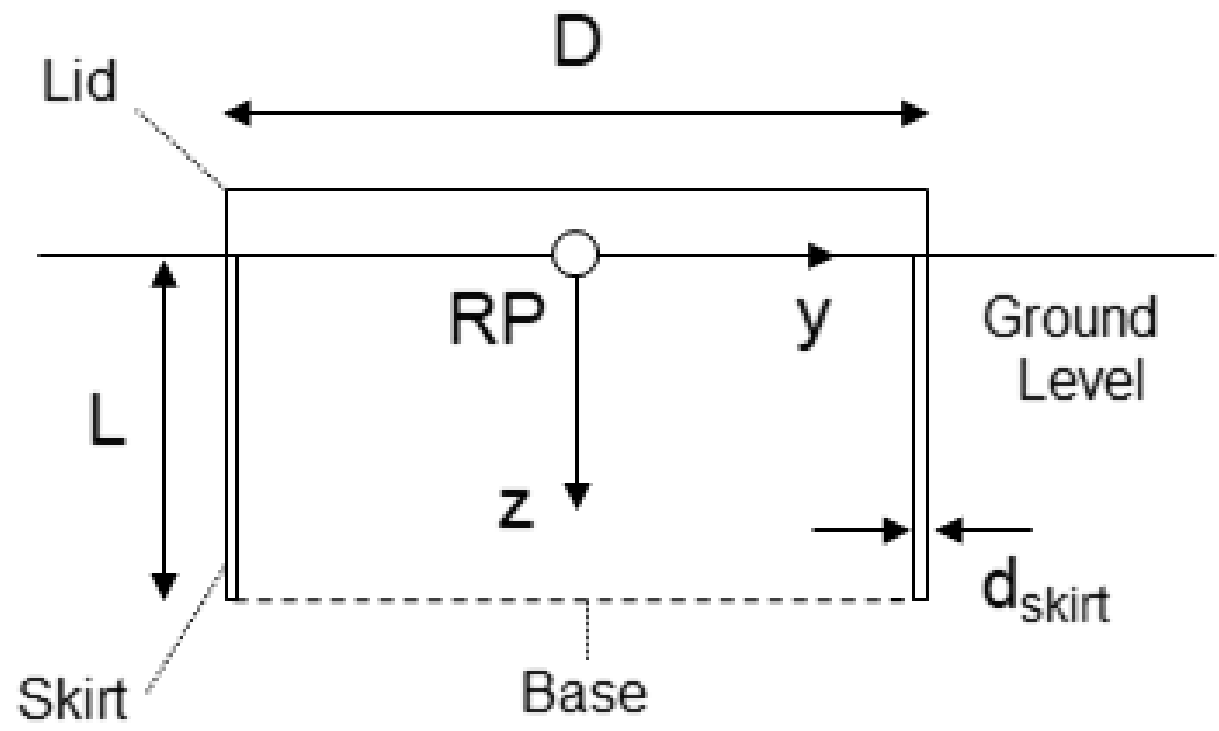

(a)

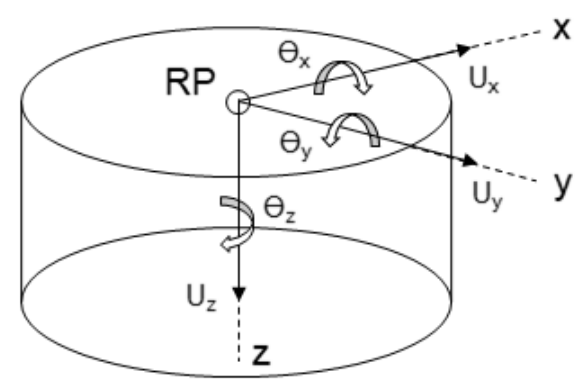

(b)

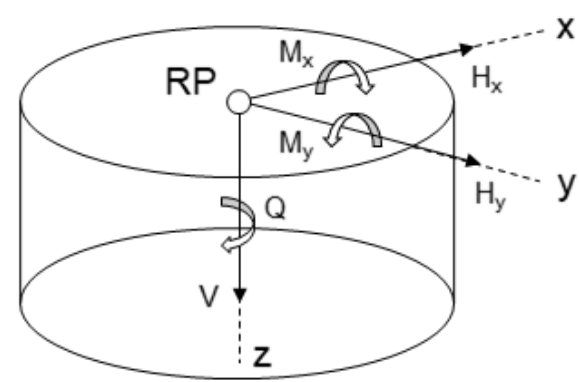

(c)

Figure 1; (a) Vertical cross section view of a caisson foundation with diameter $\boldsymbol{D}$, skirt length $\boldsymbol{L}$ and skirt thickness $\boldsymbol{d}_{\text {skirt }}$. RP indicates the reference point and origin of the $(x, y, z)$ coordinate system (b) global displacements $\left(\boldsymbol{U}_{\boldsymbol{x}}, \boldsymbol{U}_{\boldsymbol{y}}, \boldsymbol{U}_{z}\right)$ and rotations $\left(\boldsymbol{\Theta}_{x}, \boldsymbol{\Theta}_{y}, \boldsymbol{\Theta}_{z}\right)$ at the RP (c) loads $\left(\boldsymbol{H}_{x}, \boldsymbol{H}_{\boldsymbol{y}}, \boldsymbol{V}\right)$ and moments/torque $\left(\boldsymbol{M}_{\boldsymbol{x}}, \boldsymbol{M}_{\boldsymbol{y}}, \boldsymbol{Q}\right)$ applied at the RP. Rotations and moments are defined with right-hand rule conventions with respect to the $(x, y, z)$ coordinate system. 


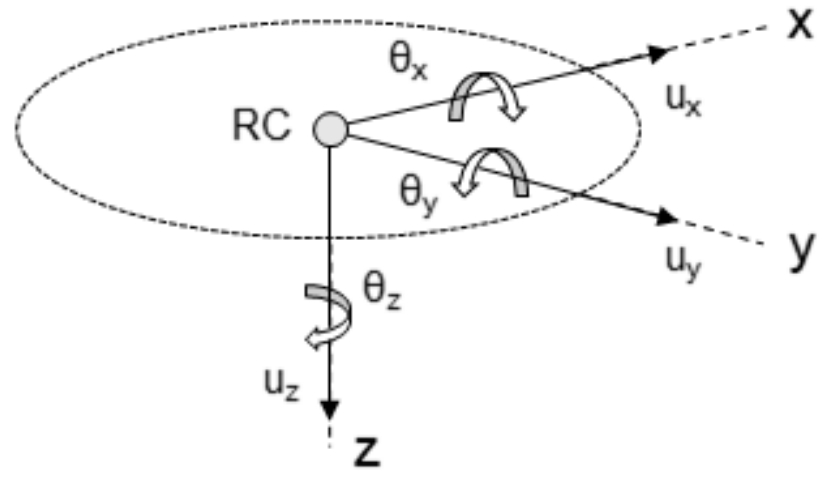

(a)

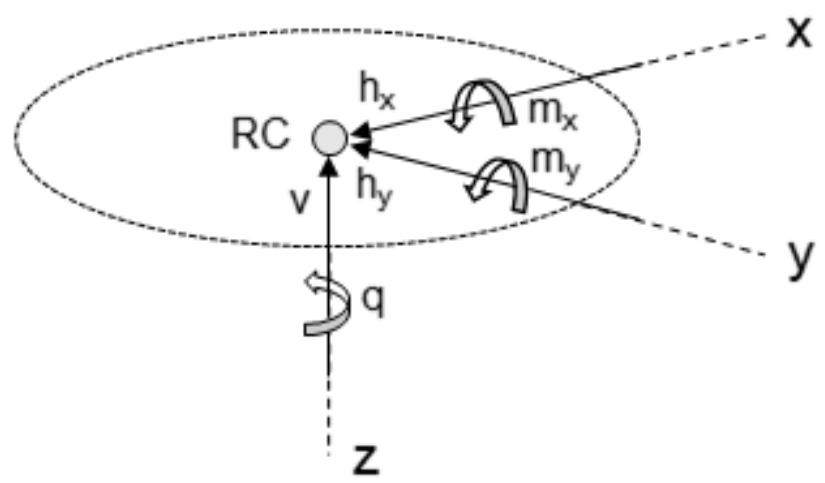

(b)

Figure 2; Schematic diagram of a caisson cross section. $\mathrm{RC}$ is the centre (and reference point) of the cross section; (a) displacements $\left(\boldsymbol{u}_{x}, \boldsymbol{u}_{y}, \boldsymbol{u}_{z}\right)$ and rotations $\left(\boldsymbol{\theta}_{x}, \boldsymbol{\theta}_{y}, \boldsymbol{\theta}_{z}\right)$ defined at RC (b) distributed loads $\left(\boldsymbol{h}_{x}, \boldsymbol{h}_{\boldsymbol{y}}, \boldsymbol{v}\right)$ and moments/torque $\left(\boldsymbol{m}_{\boldsymbol{x}}, \boldsymbol{m}_{\boldsymbol{y}}, \boldsymbol{q}\right)$ applied at RC. Rotations and moments are defined with right-hand rule conventions with respect to the $(x, y, z)$ coordinate system 


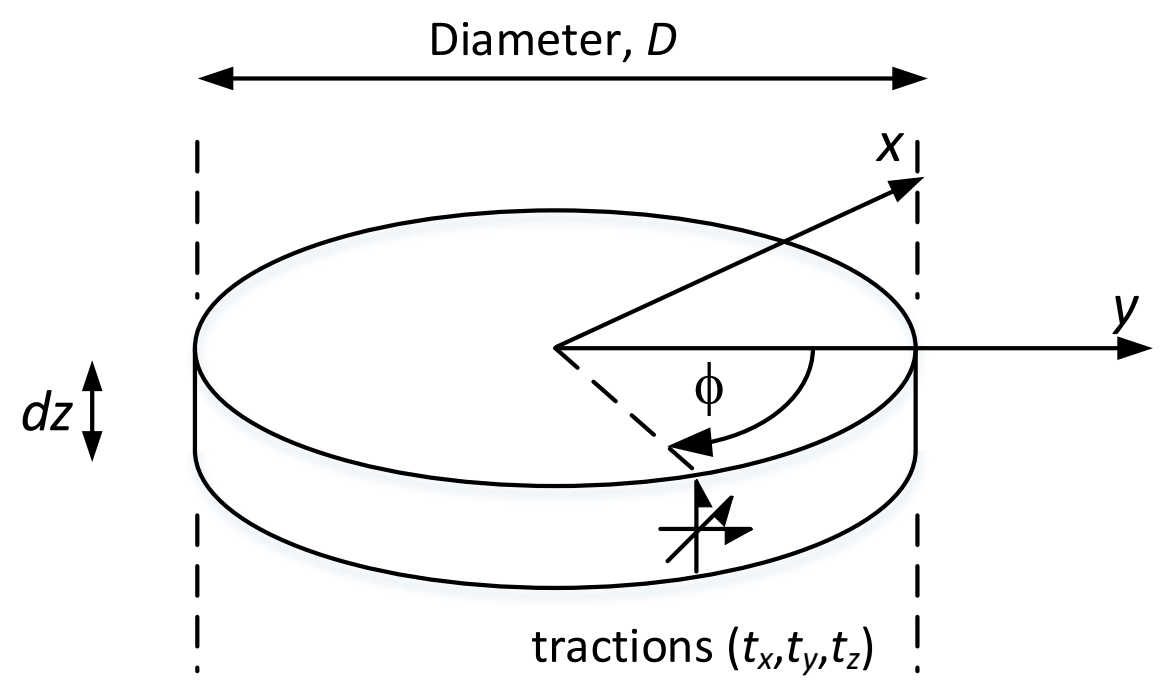

Figure 3; Horizontal slice through the caisson to illustrate the polar coordinate $\phi$ employed to determine the skirt cross section soil reactions from the computed tractions at the soil-caisson boundary 


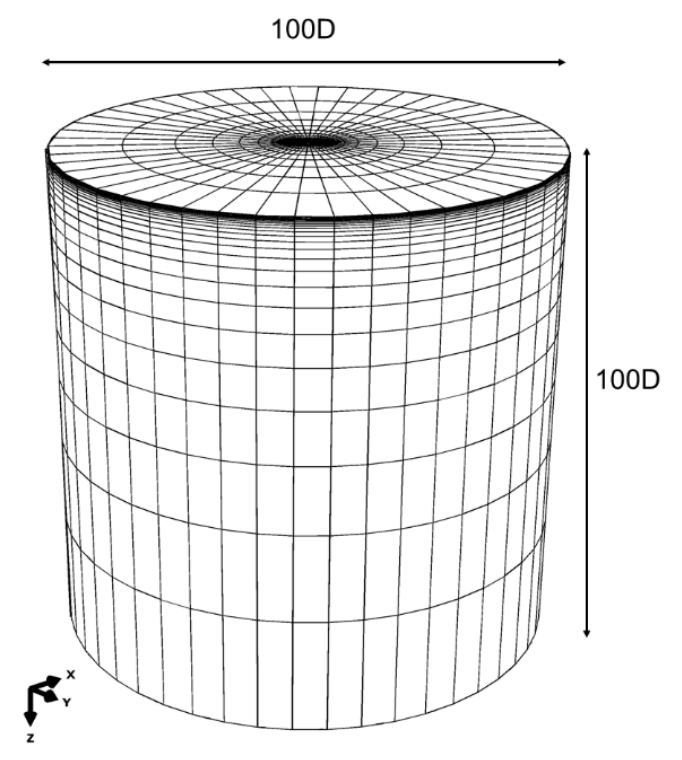

(a)

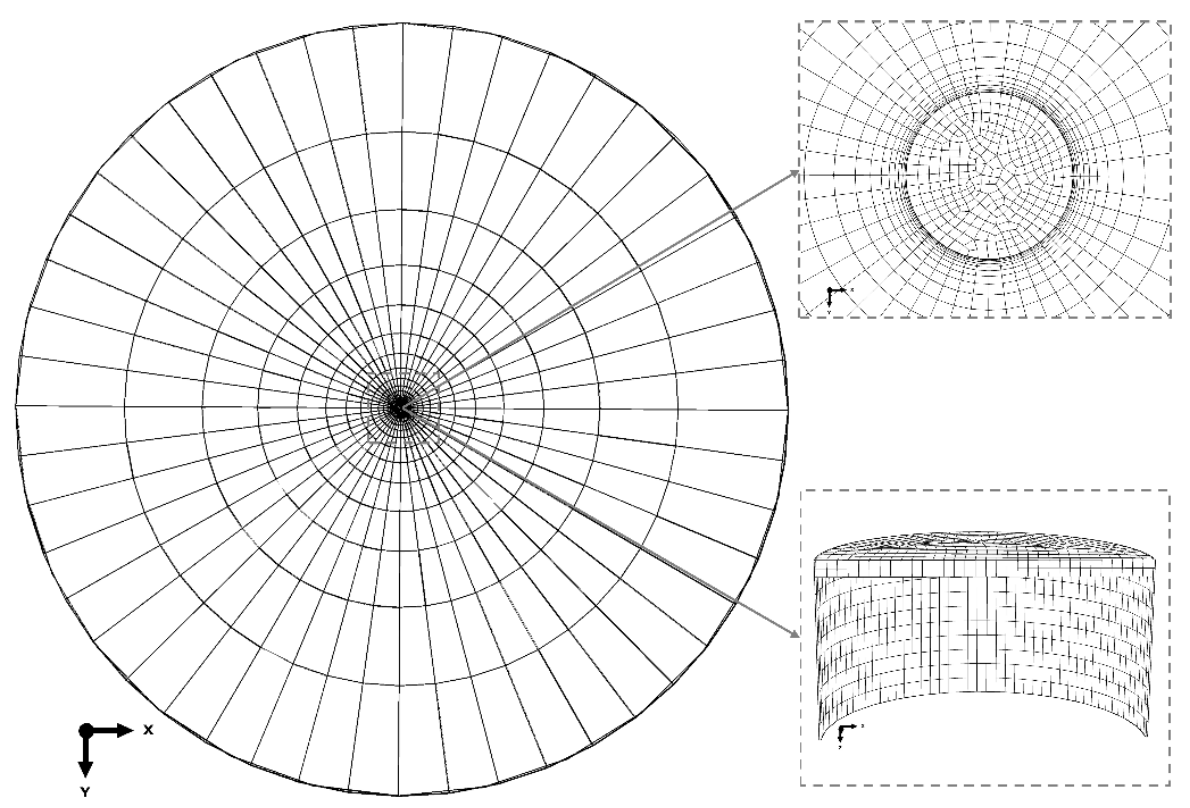

(b)

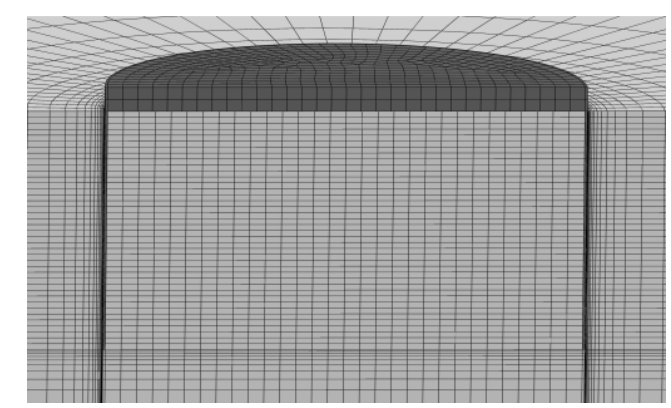

(c)

Figure 4; (a) Example 3D finite element mesh employed for the calibration calculations. The depth and width of the mesh domain are both $\mathbf{1 0 0 D}$, where $\boldsymbol{D}$ is the caisson diameter. (b) Plan view of the 3D finite element mesh, with enlarged partial views of the suction caisson foundation, (c) Enlarged partial view of the soil mesh near the suction caisson. 


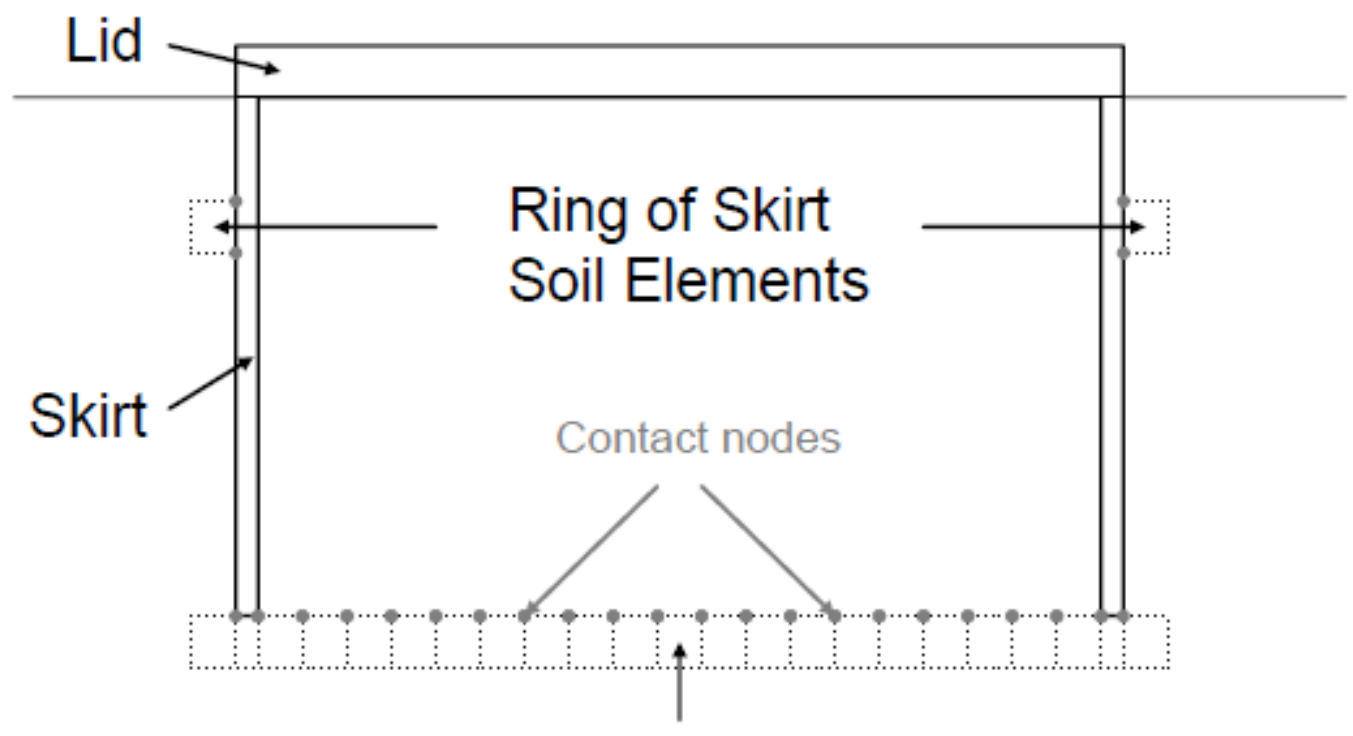

\section{Base Soil Elements}

Figure 5; Vertical cross section view of the soil elements (not to scale), from which the skirt and base and skirt soil reactions are determined. The base soil reactions include both the soil response on the skirt tip and on the soil plug. The grey markers in the figure refer to the contact nodes from which the nodal forces are extracted to determine the tractions. The ring of skirt soil elements shown in the figure is just one of several rings from which the skirt soil reactions are determined. In the current 3D finite element analyses, 10 rings are employed along the skirt. 


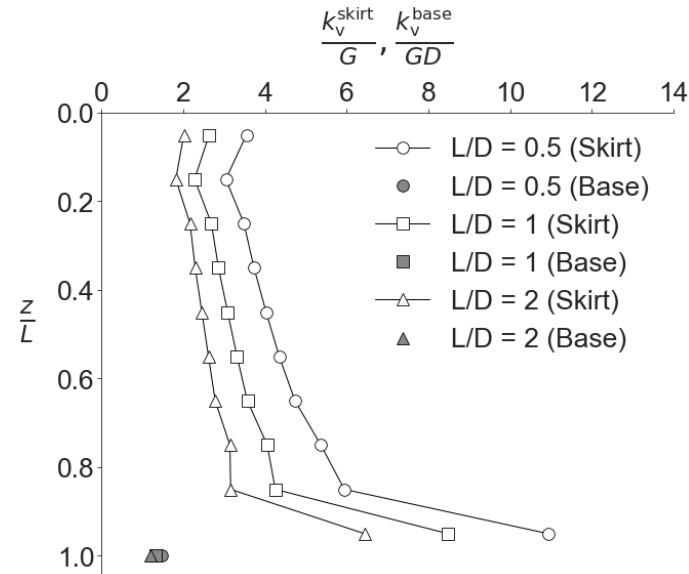

(a)

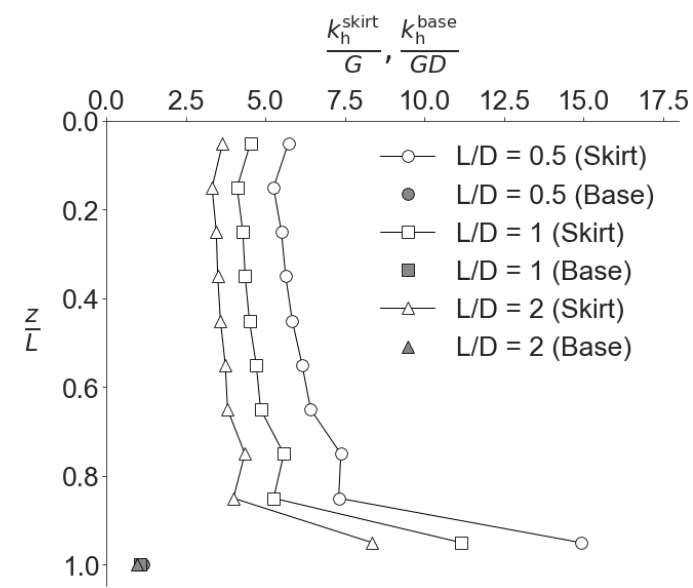

(c)

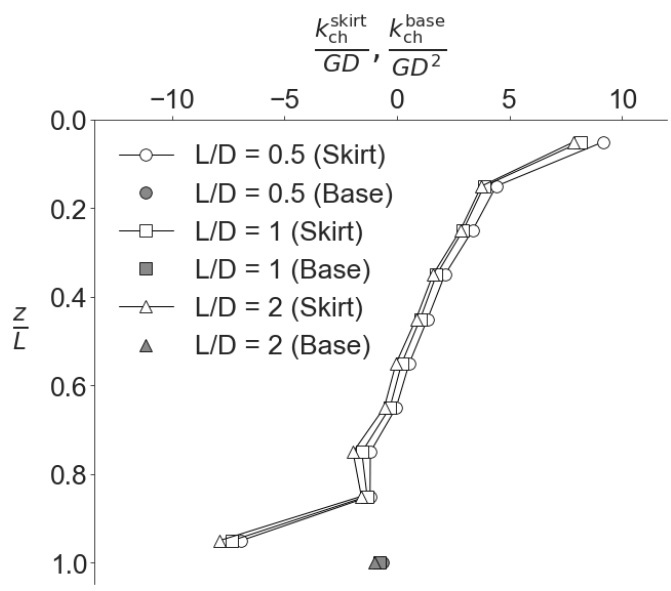

(e)

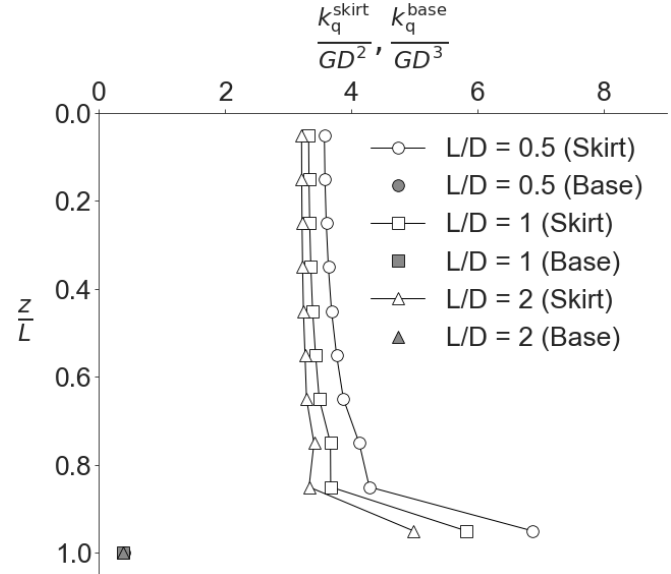

(b)

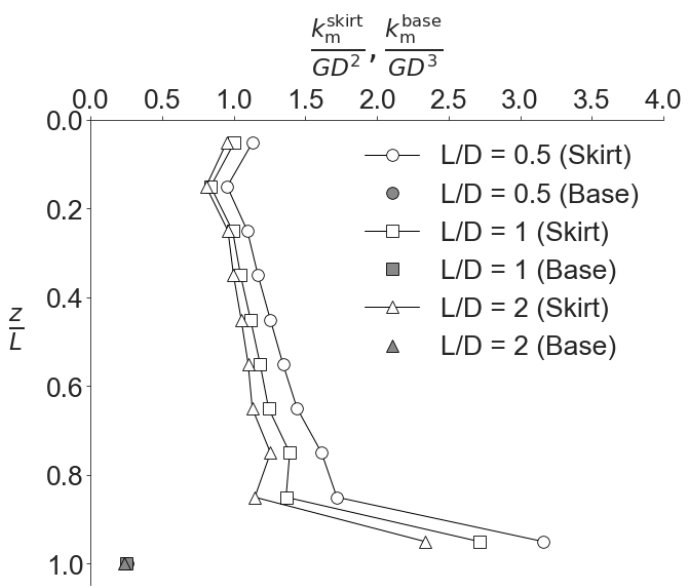

(d)

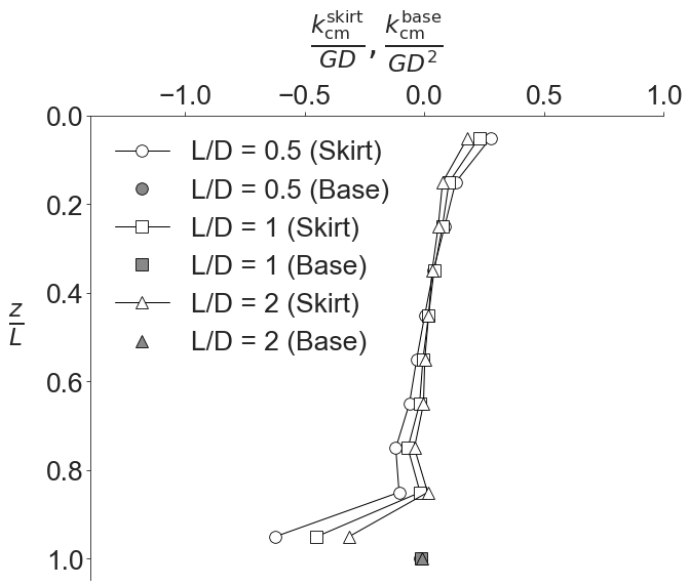

(f)

Figure 6; Normalised local stiffness coefficients for the skirt and base soil reactions for $\alpha=$ $\mathbf{0}, \boldsymbol{v}=\mathbf{0 . 2}$; (a) Vertical stiffness (b) Torsional stiffness (c) Lateral stiffness (d) Rotational stiffness (e) Lateral coupling stiffness (f) Rotational coupling stiffness 


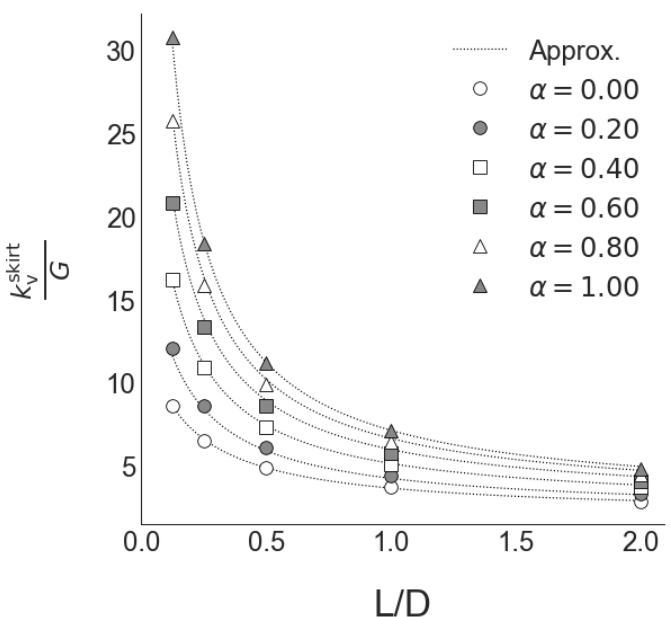

(a)

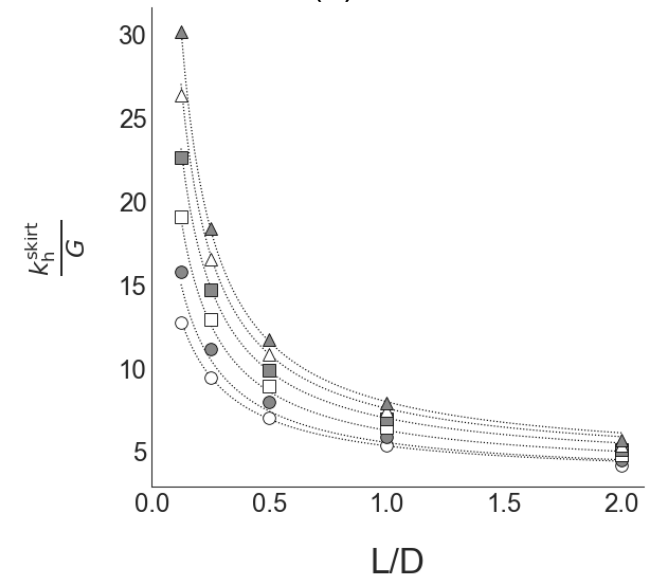

(c)

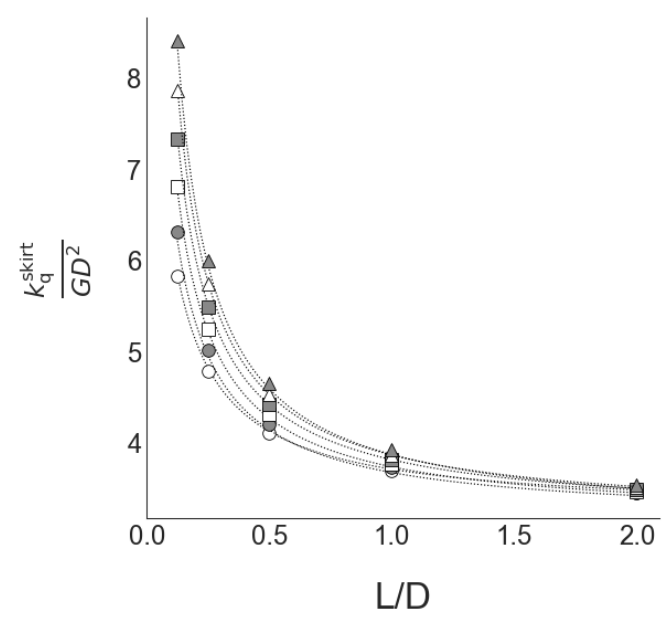

(b)

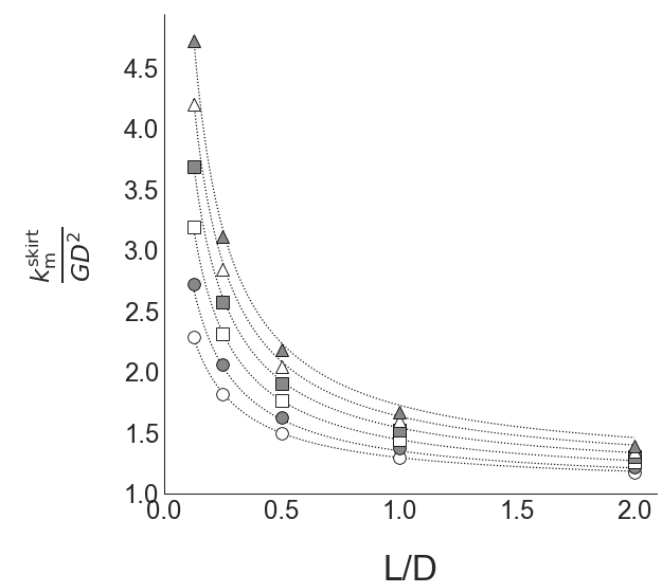

(d)

Figure 7; Normalised local stiffness coefficients for the skirt, diagonal terms only, with respect to $\boldsymbol{L} / \boldsymbol{D}$ and $\boldsymbol{\alpha}$ for and $\boldsymbol{v}=\mathbf{0 . 2}$. The dotted lines indicate the OxCaisson local stiffness coefficients (Equation 22 and Table 3). 


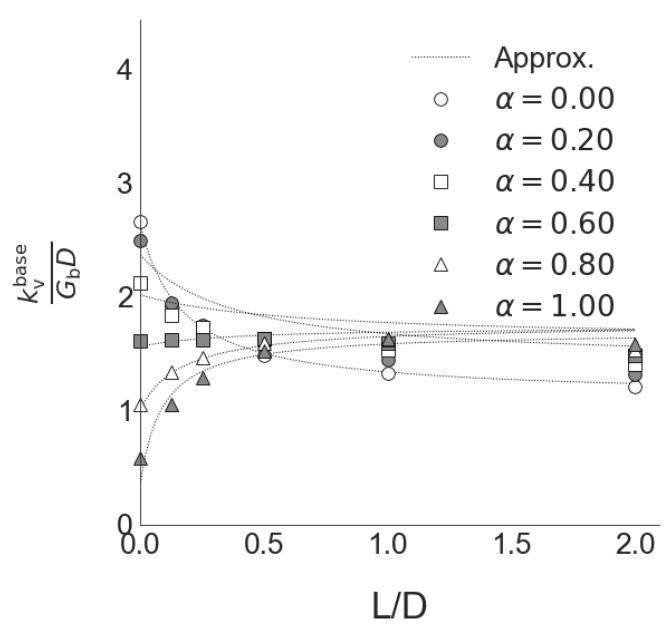

(a)

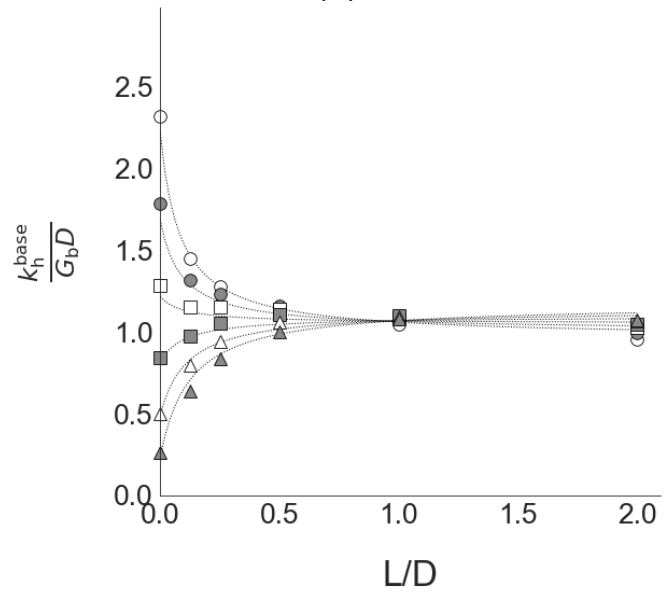

(c)

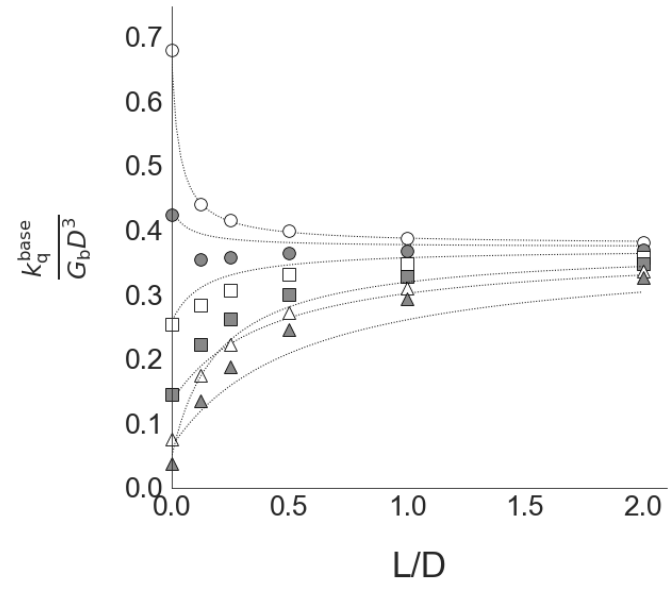

(b)

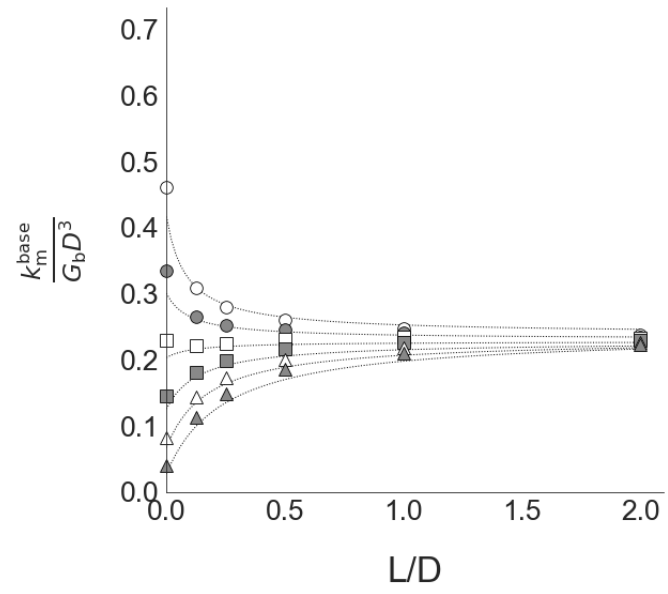

(d)

Figure 8; Normalised local stiffness coefficients for the base, diagonal terms only, with respect to $\boldsymbol{L} / \boldsymbol{D}$ and $\boldsymbol{\alpha}$ for $\boldsymbol{v}=\mathbf{0 . 2}$. The dotted lines represent the OxCaisson model for the local stiffness coefficients (Equation 23 and Table 5). 


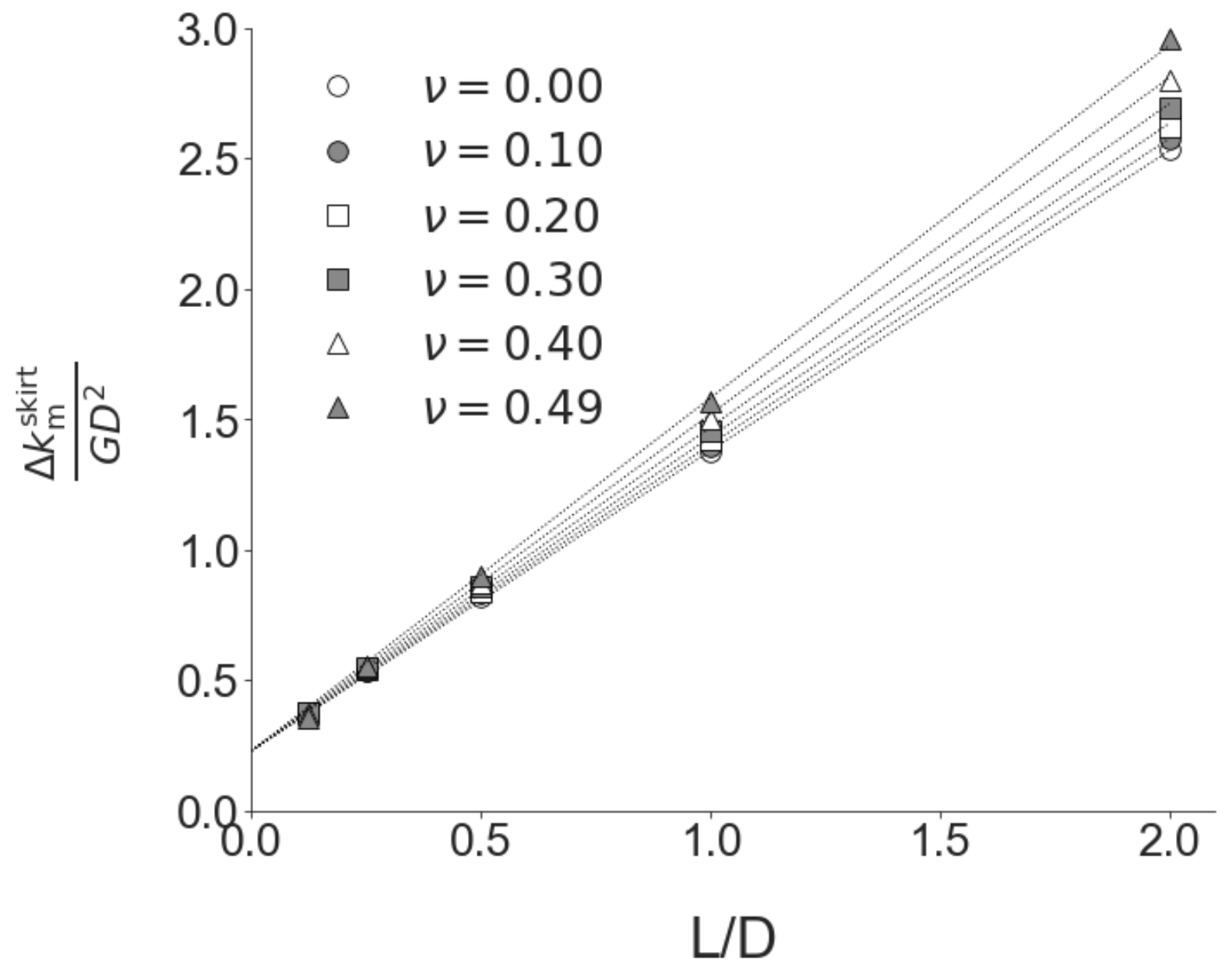

Figure 9; Artificial local rotational stiffness coefficient $\Delta \boldsymbol{k}_{m}^{\text {skirt }}$ computed from the 3D finite element results, with respect to $\boldsymbol{L} / \boldsymbol{D}$ and $\boldsymbol{v}$ for $\boldsymbol{\alpha}=\mathbf{0}$. The dotted lines are the estimations of Equation 29. 


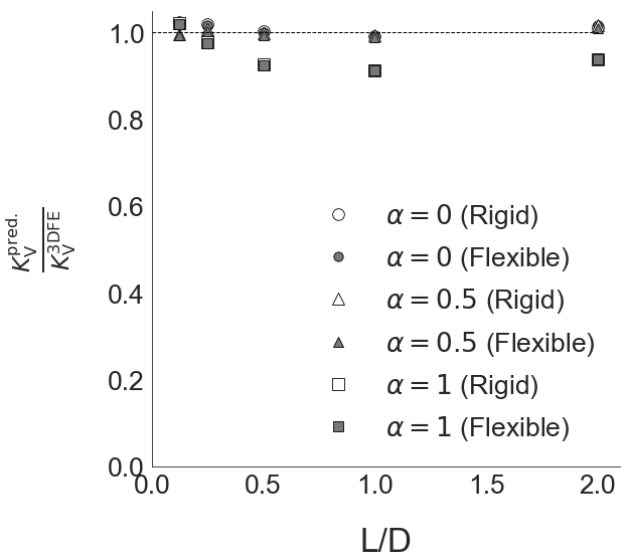

(a)

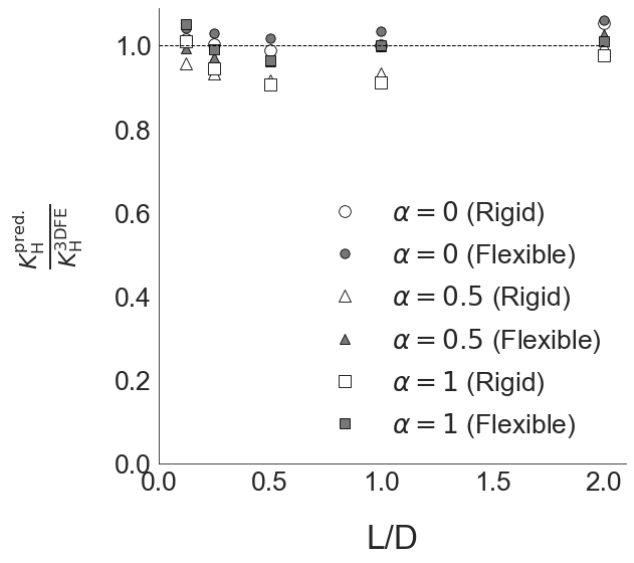

(c)

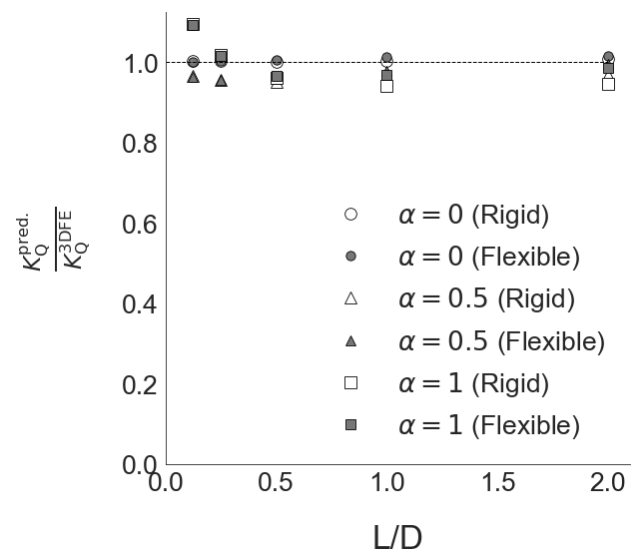

(b)

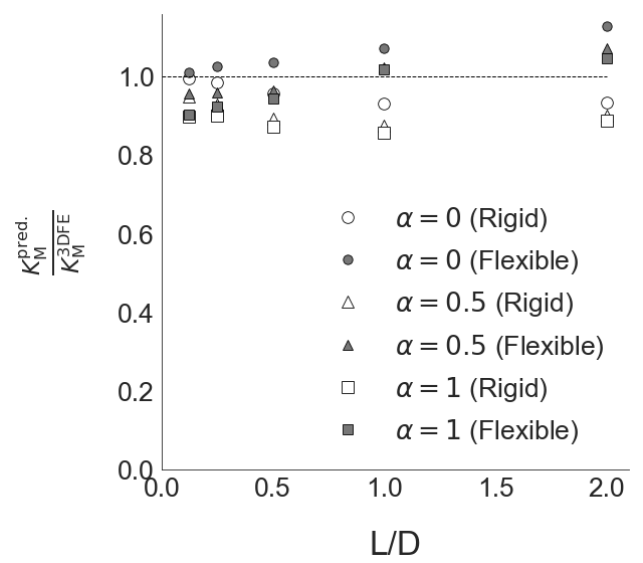

(d)

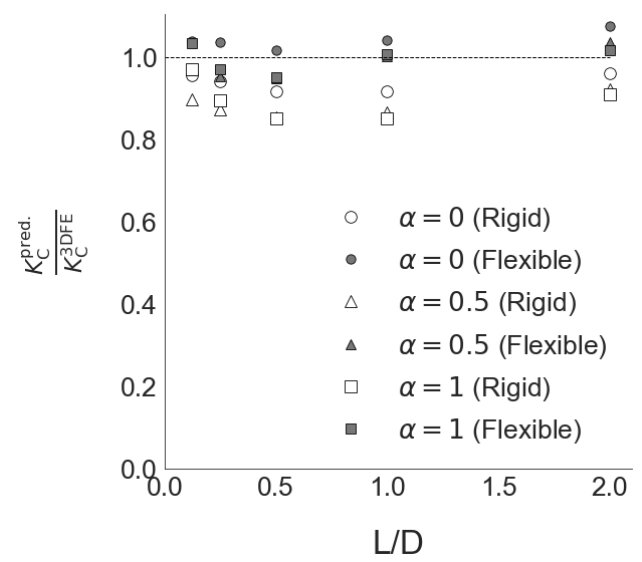

(e)

Figure 10; Comparison of the global stiffness coefficients computed by OxCaisson (normalised by the 3D finite element results), for $L / D=0.125,0.25,0.5,1,2, v=0.2$ and $\alpha=0,0.5,1$. Values of 1 represent perfect agreement between the OxCaisson computations and the 3D analyses. White symbols correspond to a fully rigid suction caisson; grey symbols correspond to a suction caisson with flexible skirt. 


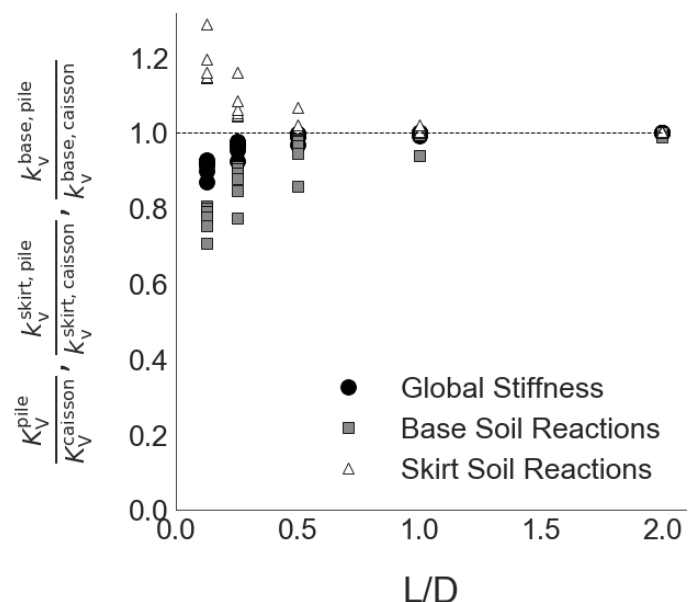

(a)

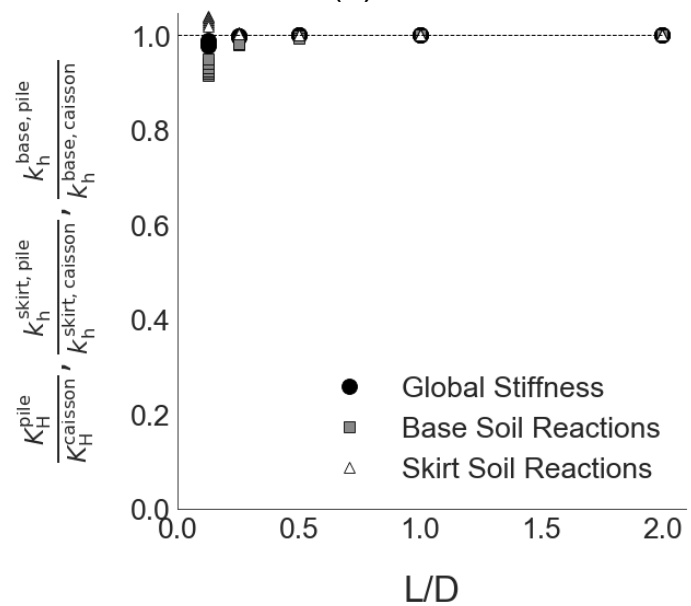

(c)

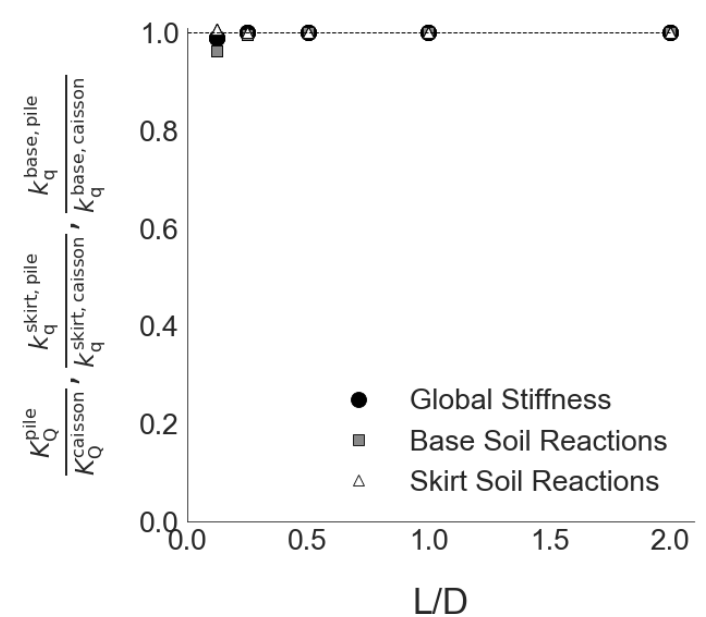

(b)

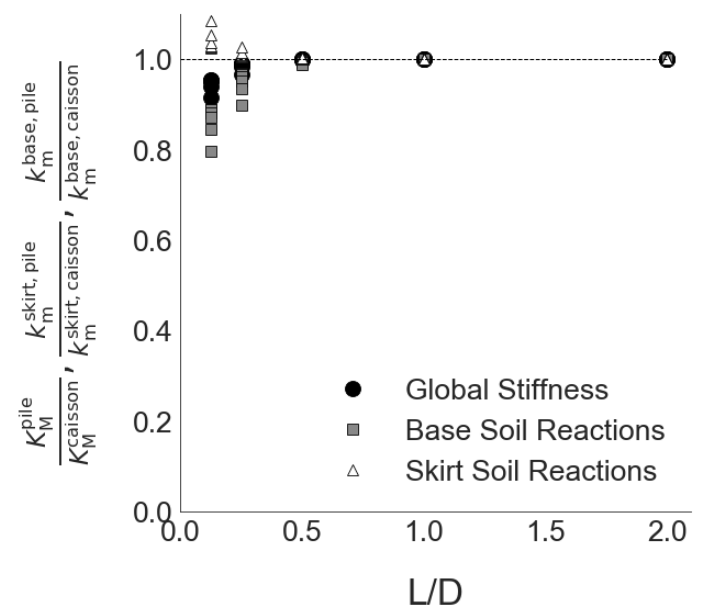

(d)

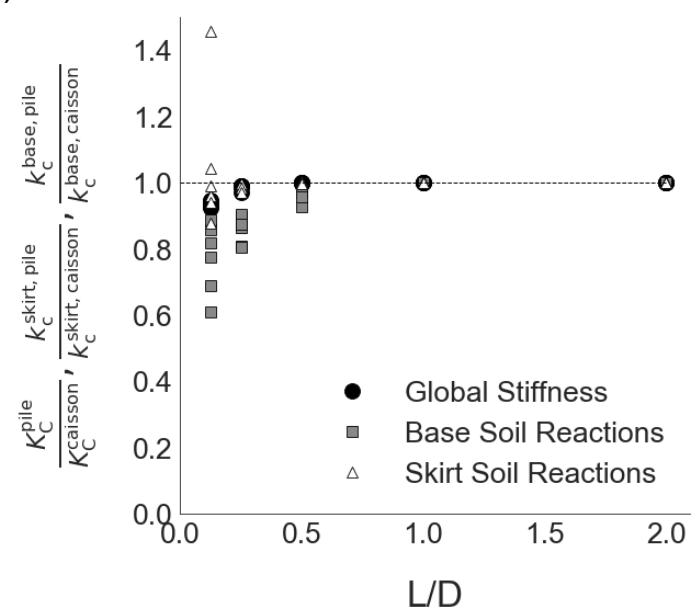

(e)

Figure 11; Comparison of the global stiffness coefficients and the local stiffness coefficients for the skirt and base soil reactions for a rigid monopile foundation, relative to those of the rigid suction caisson foundation, for $\alpha=0, L / D=0,0.125,0.25,0.5,1,2$ and $v=$ $0,0.1,0.2,0.3,0.4,0.49$. All the stiffness coefficients shown in this figure are computed using $3 \mathrm{D}$ finite element analyses. 